\title{
镧系金属催化不对称环加成反应研究进展
}

\author{
陈文坤杨定乔* \\ (华南师范大学化学与环境学院 教育部环境理论化学重点实验室 广州 510006)
}

\begin{abstract}
摘要 综述了近年来镧系金属催化不对称环加成反应的研究进展, 主要包括[4+2]、[3+2]、[2+2]和[2+1]不对称环加 成反应. 并对部分环加成反应可能的机理进行了讨论.
\end{abstract}

关键词 钵系金属催化剂; 不对称环加成; 研究进展

\section{Progress in Lanthanide Metals Catalyzed Asymmetric Cycloaddition Reactions}

\author{
Chen, Wenkun Yang, Dingqiao* \\ (Key Laboratory of Theoretical Chemistry of Environment, Ministry of Education, School of Chemistry and Environment, \\ South China Normal University, Guangzhou 510006)
}

\begin{abstract}
The recent progress in lanthanide metals catalyzed asymmetric cycloaddition reactions is reviewed, mainly including $[4+2],[3+2],[2+2]$ and $[2+1]$ asymmetric cycloaddition reactions. Moreover, the possible mechanisms of some parts of reactions are also discussed.

Keywords lanthanide metals catalyst; asymmetric cycloaddition; research progress
\end{abstract}

镧系元素是元素周期表 IIIB 族中原子系数为 57 71 的 15 种化学元素的统称. 由于镧系元素都是金属, 所以又称之为镧系金属. 近几十年来, 镧系金属有机配 合物的合成、利用及镧系金属催化具有原子经济性的重 要有机反应等方面都取得长足的发展 ${ }^{[1]}$. 镧系金属最典 型的特征是其原子半径大、电负性小, 由此决定其周围 可配位的空间大及 Lewis 酸性强等特征, 而且表现出强 亲氧性 ${ }^{[2]}$. 利用镧系金属的亲氧性、强还原性、Lewis 酸性和高配位数的特点, 在有机反应中能活化 $\mathrm{C}=\mathrm{C}$ 双 键、 $\mathrm{C}=\mathrm{O}$ 双键和 $\mathrm{C}=\mathrm{N}$ 双键, 而且由于其金属离子半径 大、配位数高, 更有利于底物的活化和配位等特点, 在 催化有机化学反应中, 显示出独特的性能. 这促使化学 家们对镧系金属催化体系兴趣并进行深入地研究 ${ }^{[3 \sim 6]}$.

环加成反应(Cycloaddition Reaction)是合成环状分 子的一种双分子反应. 最常见的环加成类型, 除了包括 $[4+2]$ 环加成外, 还包括 $[3+2] 、[2+2]$ 和 $[2+1]$ 等. 环加 成反应的主要特点是将不饱和链状化合物直接转变成
环状化合物，包括三元环、四元环到九元环、十元环等， 且原子利用率高, 是构建复杂环状分子最有效的方法之 一. 不对称催化有机合成是制备手性化合物和手性药物 的重要方法之一, 而不对称环加成反应增强了对环加成 反应过程手性的立体控制，在天然产物的全合成、药物 合成化学及工业生产等领域有着广泛的应用 ${ }^{[72]}$, 因此 镧系金属在不对称环加成反应中具有很好潜在的应用 前景. 在不对称催化有机反应发展初期, 化学家们主要 集中在传统过渡金属不对称催化合成反应的研究，直到 1983 年, Danishefsky 课题组 ${ }^{[13,14]}$ 首次报道了镧系金属配 合物催化不对称反应研究, 他们通过天然产物 $D$-樟脑 的 $\beta$-二酮衍生物与镧系金属 $\mathrm{Eu}$ 形成的配合物 $\mathrm{Eu}(\mathrm{hfc})_{3}$ 不对称催化 Danishefsky 共轭二烯与苯甲醛的杂 DielsAlder (DA)反应. 目前锞系金属催化不对称环加成反应 的研究主要集中在 $[4+2] 、[3+2] 、[2+2]$ 和 $[2+1]$ 等. 使 用镧系金属配合物不对称催化环加成反应具有区域选 择性好、对映选择性高、转化率高等优点, 这对于手性

\footnotetext{
* E-mail: yangdq@scnu.edu.cn

Received April 3, 2016; revised April 29, 2016; published online May 19, 2016.
}

Project supported by the National Natural Science Foundation of China (Nos. 21172081, 21372090), the Natural Science Foundation of Guangdong Province (No. S2013020013091) and the City of Guangzhou Science and Technology Plan Projects (No. 156300018).

国家自然科学基金(Nos. 21172081, 21372090)、广东省自然科学基金重点(No. S2013020013091)和广州市科技计划(No. 156300018)资助项目. 
药物及天然产物的全合成具有一定的科学意义和应用 前景.

本课题组主要从事金属催化有机合成反应, 已经发 表了铑 ${ }^{[15]} 、 \mathrm{c}^{[}{ }^{[16]}$ 、铱 ${ }^{[17]}$ 、钯 ${ }^{[18]}$ 、镍 ${ }^{[19]}$ 和铂 ${ }^{[20]}$ 等过渡金 属催化环加成反应的综述文章, 但对近年来锞系金属不 对称催化环加成反应的研究进展没有归纳总结. 本文将 综述镧系金属催化不对称环加成反应最新研究进展. 重 点讨论锞系金属在不对称催化 $[4+2] 、[3+2] 、[2+2]$ 和 $[2+1]$ 环加成反应, 并对部分可能的反应机理进行了 讨论.

\section{1 镧系金属催化不对称[4+2]环加成反应}

自 1928 年 DA 反应被德国化学家 Diels 与其学生 Alder 发现以来, 已得到广泛的研究和改进 ${ }^{[21]}$. DA 反应 是典型的 $[4+2]$ 环加成反应, 在大多数情况下, 由于成 环的过渡态是同面一同面相互作用，能通过分析进攻试 剂的途径而确定其立体化学. 不对称 $[4+2]$ 环加成反应 是合成光学活性的环已烯衍生物及六元杂环体系最重 要的方法之一, 对于合成许多重要的手性砌块和天然产 物合成中间体起到十分重要的作用 ${ }^{[22,23]}$. 在相关的报道 中, 镧系金属不但能很好地催化 $[4+2]$ 环加成反应, 还 能体现出良好的立体选择性.

\section{1 传统烯烃参与的不对称 $[4+2]$ 环加成反应}

2004 年, Desimoni 课题组 ${ }^{[24]}$ 报道了用手性配体吡啶 双噁唑啉 $(\mathrm{PYBOX} ， 4)$ 与镧系金属三氟甲磺酸盐 $\mathrm{Ln}(\mathrm{OTf})_{3}(\mathrm{Ln}=\mathrm{Yb}, \mathrm{Ho}, \mathrm{Eu}, \mathrm{Pr}, \mathrm{La}, \mathrm{Lu})$ 形成的配合物作 为手性催化剂催化 $\alpha, \beta$-不饱和 $N$-酰基噁唑烷酮(1a) 与环 戊二烯(2)的 DA 反应, 生成具有六元环的加成产物, 后 来 Desimoni 课题组 ${ }^{[25,26]}$ 尝试使用新型 PYBOX 作为手性 配体, 以 $\operatorname{Ln}(\mathrm{OTf})_{3}-\mathrm{PYBOX}$ 形成的配合物催化该反应 (Eq. 1). 研究发现: 配体 4a 中羟基保护基( $\left.\mathrm{Si}-\mathrm{Pr}_{3}\right)$ 的引 入对镧系金属催化的 DA 反应有着显著的影响, 不但能 防止羟基在形成锞系金属配合物的过程中产生干扰，而 且配体空间位阻的增大, 反应能获得更好的立体选择 性.

2005 年, Fukuzawa 等 ${ }^{[27]}$ 报道了通过 Sm(II)催化邻位 取代的噁唑啉二茂铁甲醛 $\mathbf{5}$ 的频哪醇偶联反应, 生成了 新的手性配体 $(1 R, 2 R)-1,2-$ 双 (2-(4,5-二氢噁唑啉)二茂铁) 频哪醇 (6) (Eq. 2). 他们以 $\mathrm{Yb}(\mathrm{OTf})_{3}$ 与 $\mathbf{6}$ 形成的配合物手 性催化剂催化 $\alpha, \beta$-不饱和 $N$-酰基噁唑烷酮(1b)和环戊二 烯(2)的不对称 $[4+2]$ 环加成反应, 得到环加成产物 $\mathbf{3 b}$ (Eq. 3). 研究发现：在不同的镧系金属化合物中, $\mathrm{Yb}(\mathrm{OTf})_{3}$ 具有最好的催化效果, 该反应获得较高的产率 $(95 \%)$ 和中等程度的对映选择性 $(80 \% e e)$. 而且产物的 立体构型以 endo 构型为主. 在进一步探索反应条件后
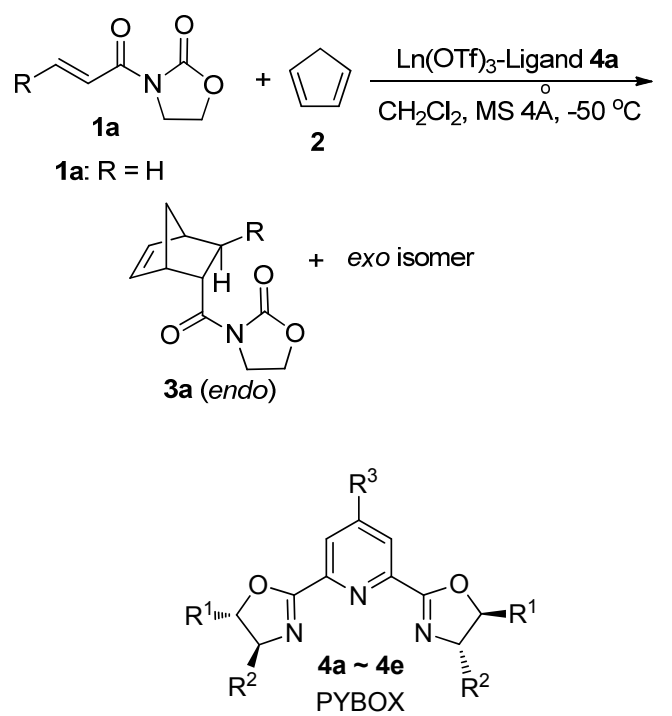

4a: $\mathrm{R}^{1}=\mathrm{Ph} ; \mathrm{R}^{2}=\mathrm{CH}_{2} \mathrm{OSi}-\mathrm{Pr}_{3}$

4b: $\mathrm{R}^{1}=\mathrm{H} ; \mathrm{R}^{2}=i-\mathrm{Pr}, t-\mathrm{Bu}, \mathrm{Ph}, \mathrm{PhCH}_{2}$; $\mathrm{R}^{3}=\mathrm{Cl}, \mathrm{Br}, \mathrm{CF}_{3}$

4c: $\mathrm{R}^{1}=\mathrm{R}^{3}=\mathrm{H} ; \mathrm{R}^{2}=\mathrm{Ph}$

4d: $\mathrm{R}^{1}=\mathrm{R}^{3}=\mathrm{H} ; \mathrm{R}^{2}=i-\mathrm{Pr}$

4e: $R^{1}=R^{2}=P h ; R^{3}=H$

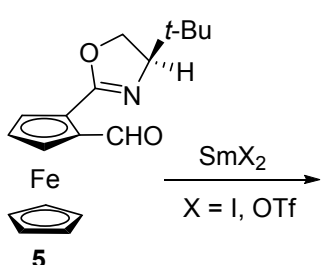

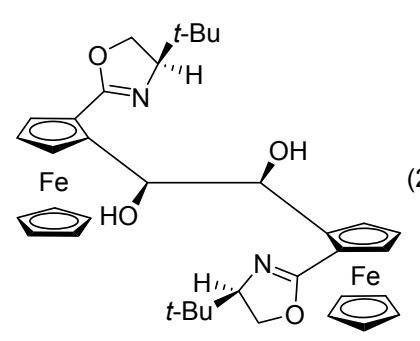

$6(R, R) \quad$ up to $76 \%$ de
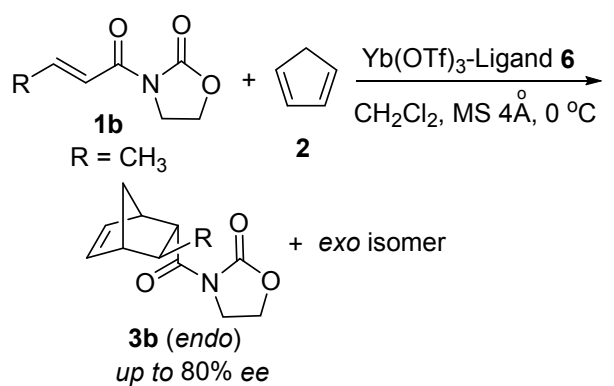

发现，在反应中加入添加剂 2,6-二甲基吡啶，反应的对 映选择性会大幅降低, 对映体过量值只有 $7 \%$ ee .

2006 年, 李灿等 ${ }^{[28]}$ 在 PYBOX 配体上进行改性, 得 到新型配体 $4 \mathbf{b}$, 并与 $\mathrm{Sc}(\mathrm{OTf})_{3}$ 和镧系金属三氟甲磺酸盐 形成配合物催化 $\alpha, \beta$-不饱和 $N$-酰基噁唑烷酮(1a)与环戊 二烯(2)的 DA 反应(Eq. 1). 他们通过在 $\mathbf{4 b}$ 的吡啶环上连 接吸电子取代基 $\mathrm{R}^{3}$, 并且在噁唑环上改变具有不同空 间位阻的取代基 $\mathrm{R}^{2}$, 使环加成反应获得更好的结果. 新 配体 $4 \mathrm{~b}$ 的应用, 克服了以往研究中反应条件苛刻和催 化剂用量多等缺点，成功地实现了在温和的条件下，反 
应物在 5 分钟内完全转化为环加成产物. 而且催化量仅 为 $1 \sim 5 \mathrm{~mol} \%$ ，产物的对映体过量值高达 $96 \%$ ee .

2008 年, Nishida 课题组 ${ }^{[29]}$ 以 $(S)-1,1^{\prime}$-(2,2'-二酰胺基) 联䒬 (BINAMIDE，9) 作为手性配体，该配体 9 与 $\mathrm{Yb}(\mathrm{OTf})_{3}$ 形成配合物催化 Danishefsky 共轭二烯 7 与 $\alpha, \beta-$ 不饱和 $N$-酰基啞唑烷酮 $\mathbf{1}$ 的 DA 反应, 得到具有六元环 的环加成产物 8 (Scheme 1). 研究表明: 在 Yb(III)-(S)-BINAMIDE 镧系金属手性催化剂催化下，该 反应产物立体构型专一, 为 exo 构型. 而且在反应中能 实现反应物的完全转化, 原子经济性好, 产物的对映体 过量值高达 $94 \%$ ee.

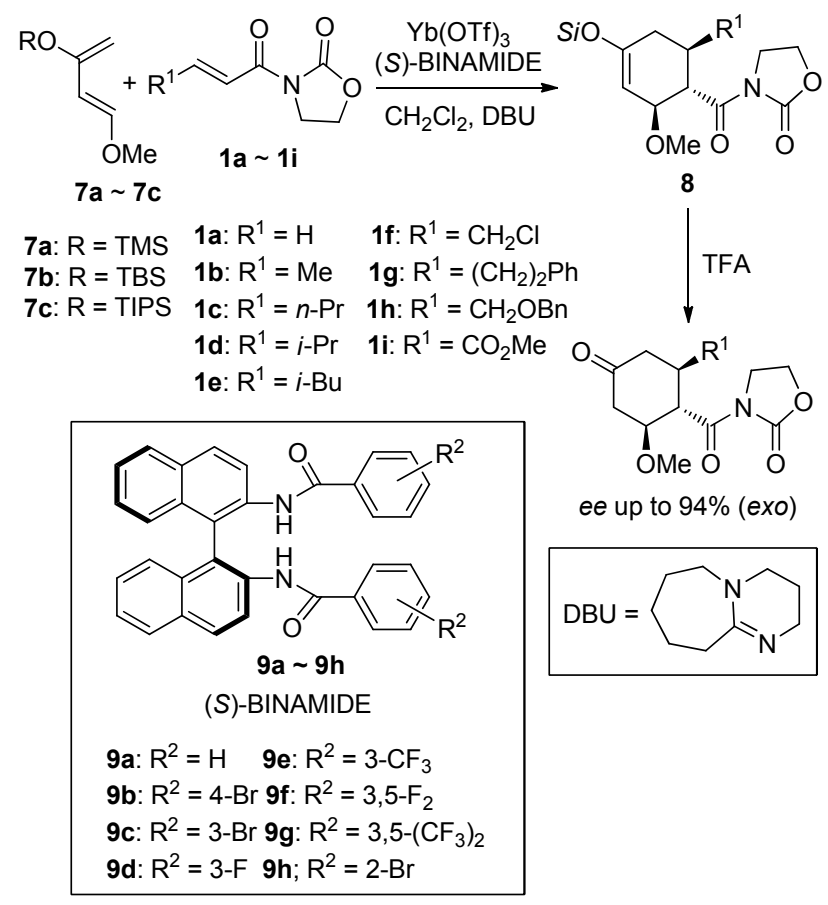

图式 1 环加成产物 $\mathbf{8}$ 的合成

Scheme 1 Synthesis of the cycloaddition product 8

Nishida 等发现, 配体9苯环上不同的取代基和取代 位置对反应的结果有着显著的影响. 总体而言, 当配体 9 苯环上的取代基 $\mathrm{R}^{2}$ 为吸电子取代基时, 有利于提高反 应活性和对映选择性(表 1, Entries 2 7). 当苯环上 3,5 位上存在两个 $\mathrm{CF}_{3}$ 取代基时, 对映体过量值能提高到 94\% ee (Entry 7). 当苯环 2 位上有吸电子取代基 $\mathrm{Br}$ 时, 反应产物 $8 \mathrm{a}$ 的产率下降, 而且对映选择性低 $(2 \% e e)$ (Entry 8). 在进一步探索了双烯 7 上的羟基保护基 $\mathrm{R}$ 和 1 上取代基 $\mathrm{R}^{1}$ 对反应的影响后发现：当双烯 7 上的保护基 $\mathrm{R}$ 空间位阻较大时，只有当亲双烯 1 上取代基 $\mathrm{R}^{1}$ 位阻较 小, 反应才能取得较好的结果, 反之亦然. 对此, 作者 认为是 $\mathrm{R}^{1}$ 与保护基团 $\mathrm{R}$ 间空间位阻相互作用的结果.

2009 年, Nishida 课题组 ${ }^{[30]}$ 在手性配体 9 的基础上引 入脲基官能团, 设计合成手性配体 $(R)-1,1^{\prime}-\left(2,2^{\prime}\right.$-双脲基)
联菜(BINUREA, 10). 他们将手性催化剂 $\mathrm{Yb}(\mathrm{OTf})_{3}-(R)-$ BINUREA 用于催化 Danishefsky 共轭二烯 7 与 $\alpha, \beta$-不饱 和 $N$-酰基噁唑烷酮 $\mathbf{1}$ 的 DA 反应，生成六元环加成产物 8 (Eq. 3). 研究发现: 以含硫代脲基官能团的 $10 b$ 作为 手性配体, $\mathrm{Yb}(\mathrm{OTf})_{3}$ 催化的环加成反应并没能得到很好 的催化效果，但是含脲基官能团的 $10 \mathrm{a}$ 作为手性配体时， 却能使反应的活性和对映选择性提高, 反应产物的产率 为 $99 \%$, 对映体过量值高达 $98 \%$ ee. 后来 Nishida 等 ${ }^{[31]}$ 通过以 9f 作为手性配体, $\mathrm{Yb}(\mathrm{OTf})_{3}$ 催化 $\mathrm{DA}$ 反应成功地 合成了环加成产物 $\mathbf{8}$, 在合成天然产物 Platyphyllide 中 间体中发挥了重要的作用.

表 1 配体 9 中不同的取代基对环加成反应的影响

Table 1 Effect of different substituents of ligand 9 on the cycloaddition

\begin{tabular}{|c|c|c|c|c|c|}
\hline Entry & Ligand 9 & Catalyst $/ \mathrm{mol} \%$ & 7/equiv. & $8 \mathbf{a}^{a} / \%$ & $e e^{b} / \%$ \\
\hline 1 & 9a & 10 & 3 & 84 & 63 \\
\hline 2 & $9 \mathrm{~b}$ & 10 & 3 & 98 & 91 \\
\hline 3 & $9 \mathrm{c}$ & 10 & 3 & 90 & 84 \\
\hline 4 & 9d & 10 & 3 & Quant. & 87 \\
\hline 5 & $9 e$ & 10 & 3 & Quant. & 89 \\
\hline 6 & $9 f$ & 10 & 2 & 93 & 92 \\
\hline 7 & $9 \mathrm{~g}$ & 10 & 2 & Quant. & 94 \\
\hline 8 & $9 \mathrm{~h}$ & 10 & 3 & 48 & 2 \\
\hline
\end{tabular}

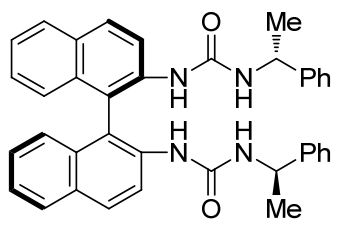

$10 a$

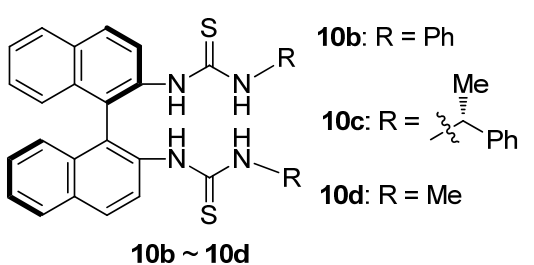

(R)-BINUREA

2013 年, Nishida 课题组 ${ }^{[32]}$ 又报道了以镧系金属化 合物 $\mathrm{Ho}\left(\mathrm{NTf}_{2}\right)_{3}$ 与 $(R)$-BINUREA (10)形成的配合物作为 手性催化剂, 催化双烯体 11 和 $\alpha, \beta$-不饱和 $N$-酰基啞唑烷 酮 $1 \mathbf{j}$ 的 DA 反应, 生成氢化咔唑衍生物 12 (Eq. 4). 研究 发现: 在 1,8-二氮杂二环[5.4.0]十一碳-7-烯(DBU)碱性 试剂作用下，反应取得良好的实验结果，而且反应只得 到 exo 构型产物 12. 通过实验结果的对比，含脲基官能 团的手性配体 10a 与 Ho 形成的配合物的催化效果比使 用含硫代嫝基的配体 10c、10d 效果差，而且在含硫代脲 基的配体中, 取代基 $\mathrm{R}$ 为甲基的 $10 \mathrm{~d}$ 在反应中表现出最 好的催化活性和对映选择性. 在进一步探索实验条件中 
发现: 在手性配体 10d 作用下, Ho 锞系金属化合物中的 阴离子对反应的催化活性影响很大, 当使用 $\mathrm{Ho}(\mathrm{OTf})_{3}$ 时, 反应产率和对映体过量值分别为 $9 \%$ 和 $16 \% e e$; 而 选用 $\mathrm{Ho}\left(\mathrm{NTf}_{2}\right)_{3}$ 时, 反应的产率和对映选择性得到大幅 度提高, 产率高达 99\%, 对映体过量值为 $94 \%$ ee.

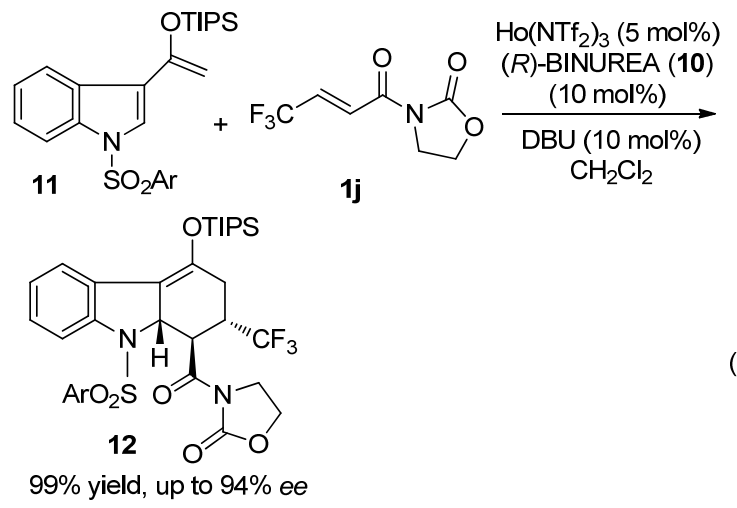

基于反应产物 12 的 exo 构型, Nishida 等提出了反应 中可能的过渡态 13 (Scheme 2). 在利用 ESI-TOF-MS 高 分辨质谱测定和分析后发现: Ho 与配体 10d 的配位形式 为 $\mathrm{Ho} / \mathrm{Ligand}=1 / 2$, 作者认为 $\mathrm{DBU}$ 试剂对于配体 10d 中的 $\mathrm{N}-\mathrm{H}$ 键具有很强的去质子化作用, 去质子化的 $\mathrm{N}$ 能与金属中心 $\mathrm{Ho}$ 配位形成 $\mathrm{Ho}\left(\mathrm{NTf}_{2}\right) /(\mathbf{1 0 d}-\mathrm{H})_{2}$ 结构, 由 于针系金属配位数高的特点, 亲双烯体 $\mathbf{1 j}$ 能与配体和 金属中心 Ho 形成 8 配位的过渡态 13. 在这个结构中, 因为配体 10d 中的䒺环在空间上位阻较大, 且同时键连 硫代嫝基, 由于空间中的相互排斥, 双烯 11 只能从位阻 小的一侧接近, 并得到 exo 构型的产物 12, 体现出良好 的对映选择性.

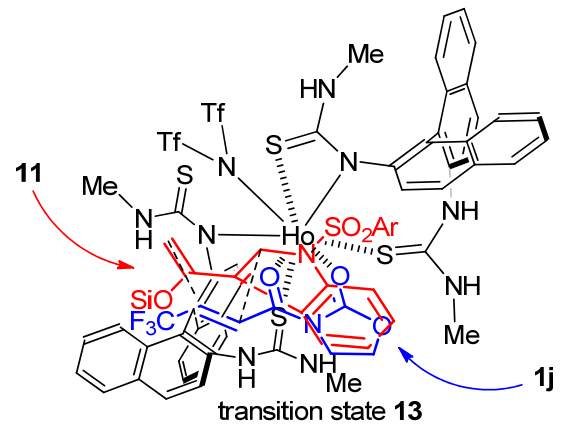

图式 $2 H o$ 催化双烯体 $\mathbf{1 1}$ 与亲双烯体 $\mathbf{1 j}$ 环加成反应可能的 过渡态

Scheme 2 Proposed transition-state model of the cycloaddition reaction between diene $\mathbf{1 1}$ and dienophile $\mathbf{1} \mathbf{j}$ catalyzed by Ho

\section{2 不对称氧杂 DA 反应}

1994 年, Mikami 等 ${ }^{[33]}$ 报道了 $\mathrm{Ln}(\mathrm{OTf})_{3}(\mathrm{Ln}=\mathrm{Yb}, \mathrm{Y}$, Sc)与双 (三氟甲烷磺酰基)酰胺形成的手性催化剂 16, 催化共轭烯烃 7d 与乙醛酸丁酯 $14 \mathrm{a}$ 的氧杂 DA 反应, 合
成二氢吡喃酮衍生物 15a (Eq. 5). 他们发现, 在该反应 体系中加入水不仅能提高反应产物的产率 $(88 \%)$, 也能 提高产物的对映体过量值 $(66 \% \mathrm{ee})$. 值得注意的是，该 针系金属催化体系的耐水性是以往文献中未见报道. 在 相关的研究中 ${ }^{[2,34]}$ ，三氟甲磺酸锞系金属化合物 $\operatorname{Ln}(\mathrm{OTf})_{3}$ 不仅在有机相，而且在水相中也可作为 Lewis 酸使用. 更重要的是，反应结束后，在反应体系中加入 水, 催化剂 $\mathrm{Ln}(\mathrm{OTf})_{3}$ 将进入水相中, 分离后, 将水蒸除 能定量回收催化剂，再进行催化循环使用，其催化活性 不会下降。

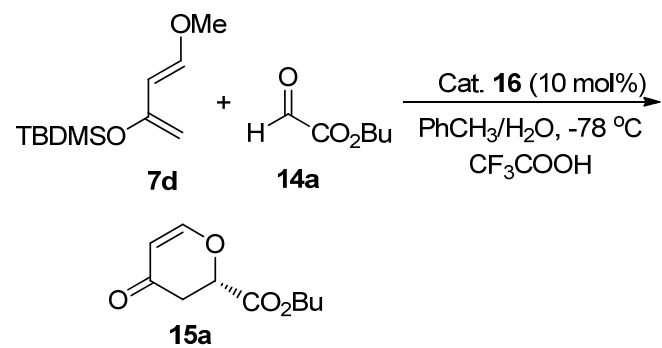

up to $88 \%$ yeild, $66 \%$ ee

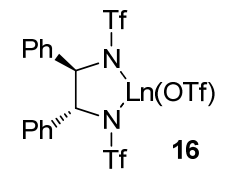

lanthanide bis-trifylamide

2000 年, 钱长涛等 ${ }^{[35]}$ 尝试以具有 $C_{2}$ 对称轴的二噁 唑啉[Bis(oxazolione)]配体与镧系金属化合物 $\mathrm{Yb}(\mathrm{OTf})_{3}$ 形成的手性催化剂 $\mathrm{Yb}(\mathrm{OTf})_{3}$-Bis(oxzolione), 催化 Danishefsky 共轭二烯 7a 与乙醛酸甲酯 14b 发生 DA 反 应, 形成二氢吡喃酮衍生物 15b (Eq. 6). 在尝试不同的 二噁唑啉手性配体后发现: 6,6'-二[2-(5-苯基-4,5-二氢噁 唑啉)]-2,2'-联吡啶 $(\mathbf{1 8})$ 与 $\mathrm{Yb}(\mathrm{OTf})_{3}$ 形成的催化剂虽然能 催化反应发生，但是对映选择性低 $(9 \% e e)$, 而且产率只 有 $46 \%$. 但是 $\mathrm{Yb}(\mathrm{OTf})_{3}$-PYBOX (4d) 在该反应中具有最 好的催化活性，目标产物的产率达 $73 \%$, 对映体过量值 为 $77 \%$ ee. 在研究反应条件中发现, $4 \AA$ 分子笁在反应中 是不能缺少的, 加入 $4 \AA$ 分子篮后, 反应的产率和立体 选择性都得到很大的提高.

2003 年, Inanaga 等 ${ }^{[36,37]}$ 报道了以锞系金属 $\mathrm{Yb}$ 与 $(R)$-联荎酚磷酸酯 $(\mathrm{BNP})$ 形成的配合物 $\mathbf{2 1}$ 催化苯甲醛 19 与 Danishefsky 共轭二烯 7a 的 DA 反应, 生成环加成产 物 6-苯基-2,3-二氢吡喃-4-酮 20 (Eq. 7). 研究发现: 21c 作为手性催化剂, 具有很好的产率和对映选择性, 对映 体过量值为 $91 \% e e$, 产率为 $92 \% .21 \mathrm{a}$ 在催化反应中同 样取得较好的结果. 而在 $\mathbf{2 1 b}$ 的催化反应中, 虽然产物 的对映体过量值只有 $57 \% \mathrm{ee}$ ，但是产物的构型却与 21a、21c 催化所得产物构型相反. 作者认为即使 21b 


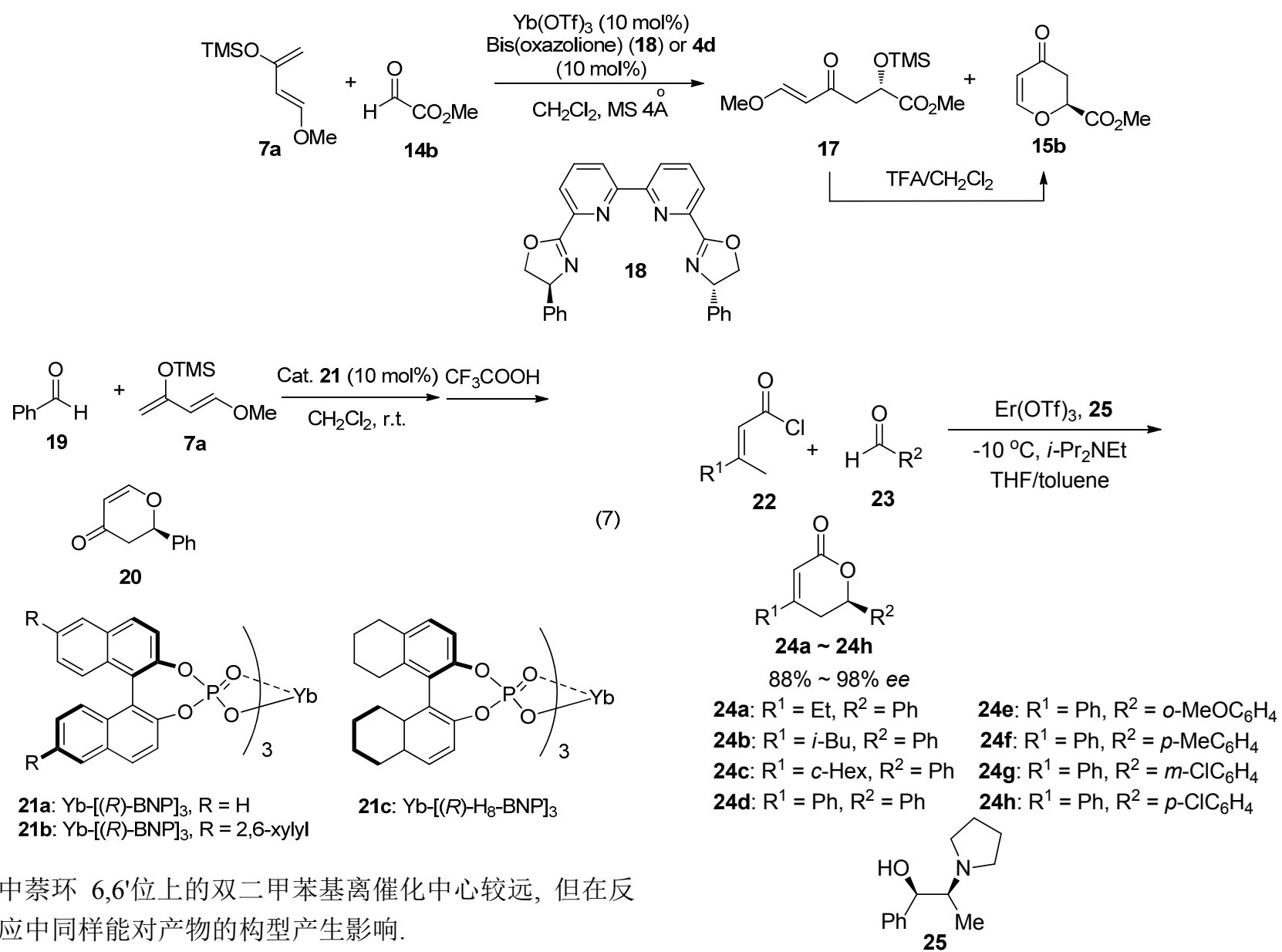

表 2 底物 22 和 23 中不同取代基对 DA 环加成反应的影响 ${ }^{a}$ Table 2 Effect of different substituents of substrates $\mathbf{2 2}$ and $\mathbf{2 3}$ on cycloaddition reactions ${ }^{a}$

\begin{tabular}{cccccc}
\hline Entry & $\mathrm{R}^{1}$ & $\mathrm{R}^{2}$ & 25/equiv. & Yield $^{b} / \%$ & $e e^{c} / \%$ \\
\hline 1 & $\mathrm{Et}$ & $\mathrm{Ph}$ & 0.2 & 62 & 95 \\
2 & $i-\mathrm{Bu}$ & $\mathrm{Ph}$ & 0.2 & 54 & 98 \\
3 & $c$ - $\mathrm{Hex}$ & $\mathrm{Ph}$ & 0.2 & 65 & 96 \\
4 & $\mathrm{Ph}$ & $\mathrm{Ph}$ & 0.1 & 64 & 94 \\
5 & $\mathrm{Ph}$ & $o-\mathrm{MeOC}_{6} \mathrm{H}_{4}$ & 0.2 & 26 & 94 \\
6 & $\mathrm{Ph}$ & $p-\mathrm{MeC}_{6} \mathrm{H}_{4}$ & 0.2 & 30 & 94 \\
7 & $\mathrm{Ph}$ & $m-\mathrm{ClC}_{6} \mathrm{H}_{4}$ & 0.2 & 78 & 93 \\
8 & $\mathrm{Ph}$ & $p-\mathrm{ClC}_{6} \mathrm{H}_{4}$ & 0.1 & 71 & 92 \\
\hline
\end{tabular}

${ }^{a}$ Compound 22 was slowly added by syringe pump over $30 \min (1: 1$ stoichiometry of both substrates). Stirring was continued for an additional 120 min. ${ }^{b}$ Isolated yield. ${ }^{c}$ Determined by chiral column HPLC.

2011 年, 冯小明课题组 ${ }^{[39]}$ 用手性配体 $N, N^{\prime}$-二氧化 物 32 与镧系金属三氟甲磺酸盐 $\operatorname{Er}(\mathrm{OTf})_{3}$ 形成手性催化 剂, 催化 $\beta, \gamma$-不饱和- $\alpha$-酮酸酯 29a 与 2,3 -二氢呋喃 30 的 不对称氧杂 DA 反应, 生成二氢吡喃衍生物 31 (Eq. 9). 在催化量仅为 $0.05 \sim 0.5 \mathrm{~mol} \%$ 的 $\mathrm{Er}(\mathrm{OTf})_{3}-32$ 配合物催 化下，该反应不但具有很好的非对映选择性 $(d r \geqslant 99$ ： 1), 而且产物的对映体过量值高达 $97 \% e e$, 产率为 $99 \%$. 研究发现: 在不同的锞系金属三氟甲磺酸盐中, 


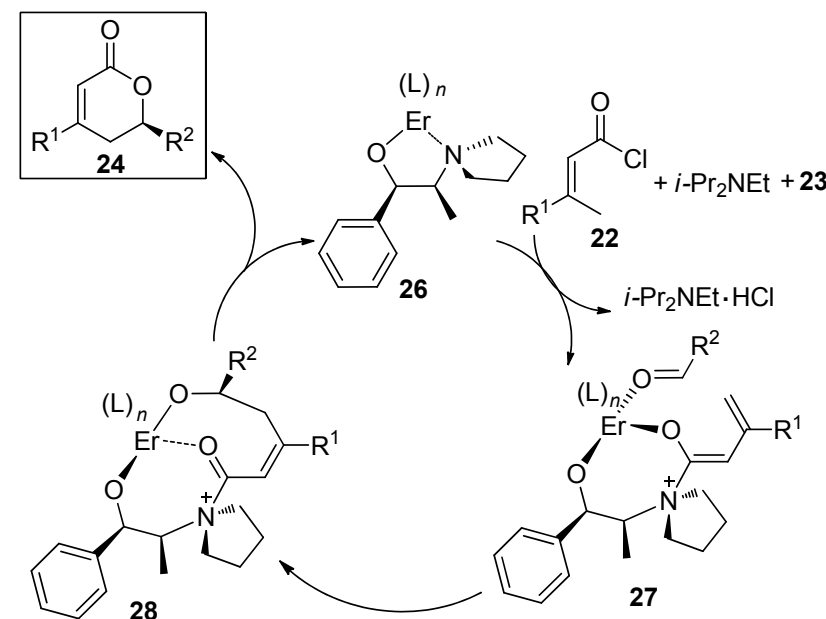

图式 $3 \mathrm{Er}(\mathrm{OTf})_{3}$ 与 $\mathbf{2 5}$ 催化合成内酯 $\mathbf{2 4}$ 可能的反应机理

Scheme 3 Plausible mechanism for $\operatorname{Er}(\mathrm{OTf})_{3}$ and 25 catalyzed formation of lactones $\mathbf{2 4}$

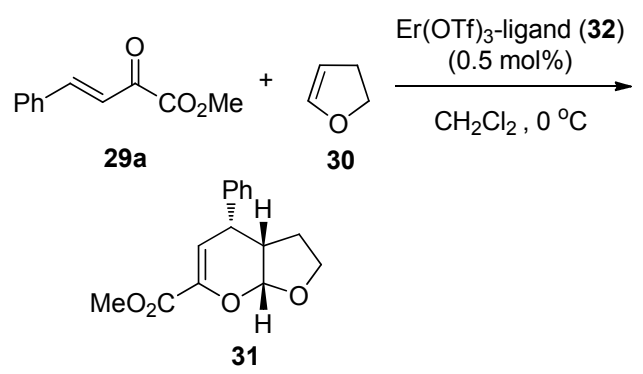

$\mathrm{Er}(\mathrm{OTf})_{3}$ 与配体 32 形成的配合物具有最好的催化效果. 而且配体 32 中芳胺上的取代基(Ar)的空间位阻对反应 有着很大的影响. 随着 32 中的 $\mathrm{Ar}$ 空间位阻的增大, 反 应的对映选择性也随之增强. 当配体为 32c 时, 配体中 的 $\mathrm{Ar}$ 空间位阻最大，不仅能使反应时间大幅降低，而且 反应具有最好的对映选择性.

同年, Wang 课题组 ${ }^{[40]}$ 以配体 $(S)$-2-氨基-3-甲基$N$-(2-吡啶)丁酰胺(36)和稀土金属 Lewis 酸 $\mathrm{M}(\mathrm{OTf})_{3}$ $(\mathrm{M}=\mathrm{La}, \mathrm{Yb}, \mathrm{Y})$ 形成的配合物, 成功地合成了新颖的双 功能催化剂. 配体 36 与金属 $(\mathrm{M}=\mathrm{La}, \mathrm{Yb}, \mathrm{Y})$ 形成分子内 紧密的配位结构, 减少了分子间的相互作用, 进而降低 了催化剂失活的可能. 他们将金属配合物用于催化环己 酮 33 与 $\beta, \gamma$-不饱和- $\alpha$-酮酸酯 29a 的氧杂 DA 反应, 生成 六氢苯并吡喃衍生物 34 (Eq. 10). 研究发现不同金属的 催化效果差别很大, 其中 $\mathrm{Sc}(\mathrm{OTf})_{3}$ 和 $\mathrm{Eu}(\mathrm{OTf})_{3}$ 只能催化
羟醛缩合反应发生, 得到产物 35 . 而 $\mathrm{La}(\mathrm{OTf})_{3}, \mathrm{Yb}(\mathrm{OTf})_{3}$ 和 $\mathrm{Y}(\mathrm{OTf})_{3}$ 不但能催化氧杂 $\mathrm{DA}$ 反应发生，获得预期的 环加成产物 34, 而且实现了对产物的手性诱导. 当金属 中心为 $\mathrm{Yb}(\mathrm{OTf})_{3}$ 时, 反应产物的产率为 $61 \%$, 对映体过 量值为 $70 \%$ ee.

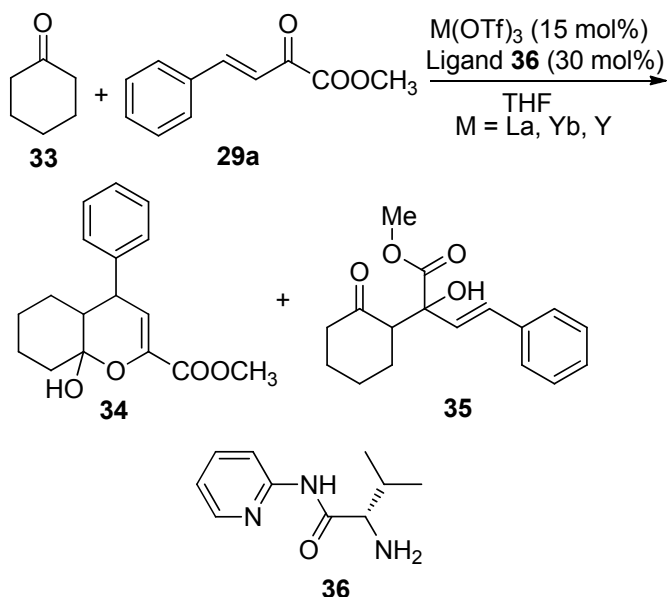

基于产物 34 为 endo 构型，并结合对催化体系的分 析, Wang 等提出可能的反应机理(Scheme 4). 首先, 配 体 36 与金属中心形成配合物 40, 40 中的一级胺能与 33 中的羰基形成具有烯胺结构的 37. 在金属中心与 29a 中 羰基配位后，由于 $\mathbf{3 8}$ 中酰胺 $\alpha$ 位上的异丙基空间位阻的 影响, 37 中的烯胺更倾向于从 $29 \mathrm{a}$ 的 $S i$-face 进攻 (Scheme 5), 进而形成 endo 构型的缩醛胺 39. 经水解生

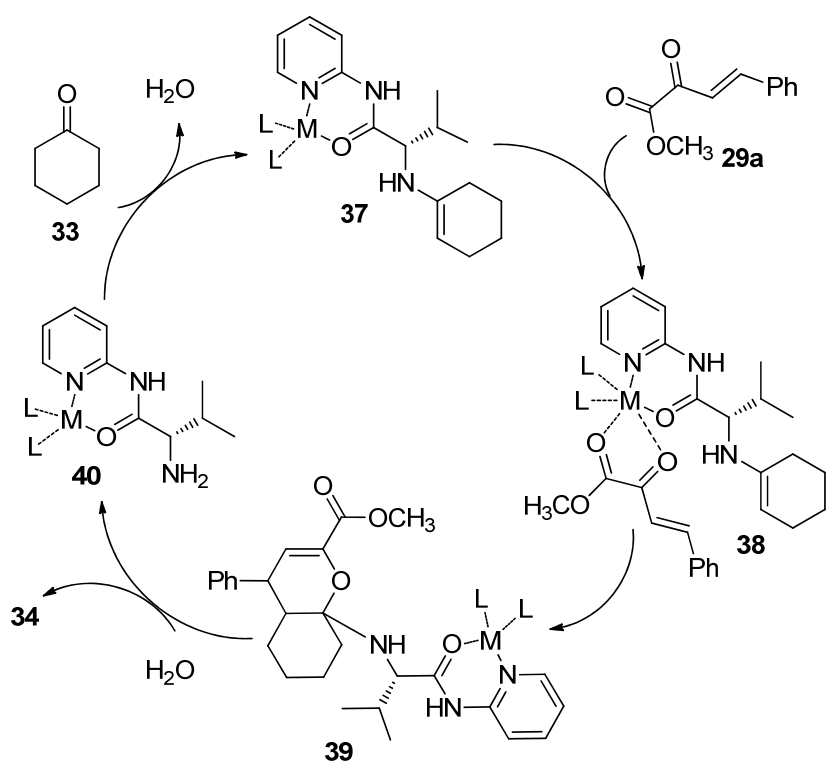

图式 4 双功能催化剂 40 催化不对称环加成反应可能的反应 机理

Scheme 4 Plausible mechanism of bifunctional catalyst 40 catalyzed asymmetric cycloaddition 


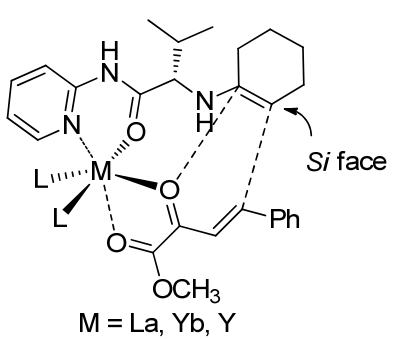

图式 5 反应中可能的过渡态

Scheme 5 Plausible transition-state in the reaction

成产物 34 后, 释放出手性配合物 $\mathbf{4 0}$, 反应得以催化循 环进行.

2015 年, Schaus 课题组 ${ }^{[41]}$ 报道了在 $\mathrm{Ho}(\mathrm{OTf})_{3}$ 与 $(+)-$ 酒石酸 45 共催化下, 异苯并吡喃乙缩醛(41)与苯乙烯基 嗍酸二异丙醇酯(42) 反应生成 $(1 S, 2 R)-1,2$-二氢-2-苯基 萗-1-甲醛(44) (Eq. 11). 作者认为该反应以 DA 反应路径 进行. 活化的双烯体 42 通过改变 LUMO 前线轨道成分 加快了环加成的反应速率. 在反应中, 亲双烯体 $\mathbf{4 2}$ 与异 苯并吡喃乙缩醛(41)形成环加成产物中间体 43 , 并在酸 性条件下生成稳定的 44. 研究发现: 单独的 $(+)$-酒石酸 (45)并不能催化环加成反应发生, 而当反应中加入镧系 金属三氟甲磺酸盐 $\operatorname{Ho}(\mathrm{OTf})_{3}$ 后，反应不但能顺利进行， 而且反应活性和对映选择性得到了很大的提高, 产物的 对映体比率甚至高达 98.5：1.5.

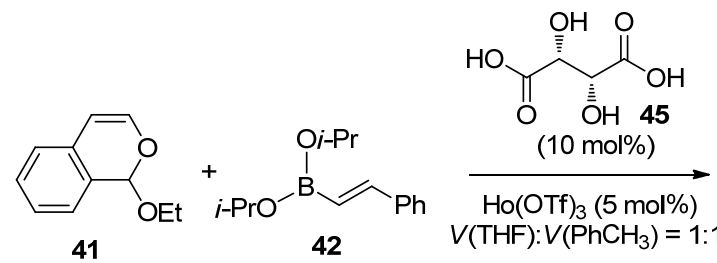<smiles>CCO[GaH]C(C)Cc1ccc2c(c1)[C@@H](CO)[C@@H](c1ccccc1)C=C2</smiles>

\section{3 不对称氮杂 DA 反应}

早在 1996 年, Kobayashi 等 ${ }^{[42]}$ 就报道了首例以催化 量的 $\mathrm{Yb}(\mathrm{OTf})_{3}$, 手性配体 $(R)-1,1^{\prime}$-联-2-萗酚(BINOL)和 DBU 等形成的配合物 49 催化亚胺 46 和乙烯基乙醚 47 的不对称氮杂 DA 反应, 生成四氢喹啉衍生物 48 (Eq. 12).

2010 年, 冯小明课题组 ${ }^{[43]}$ 报道了以 $\mathrm{Yb}(\mathrm{OTf})_{3}$-配体 32c 手性催化剂催化 Brassard 二烯 50 与亚胺 51 生成具 有氮杂六元环的 $\alpha, \beta$-不饱和己内酰胺衍生物 53 的不对 称氮杂 DA 反应(Scheme 6). 研究发现: 反应具有良好的 对映选择性，产物的对映体过量值为 $81 \% \mathrm{ee}$, 而且

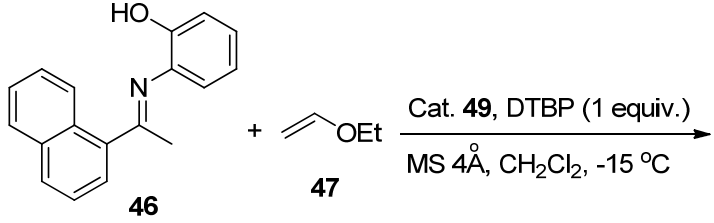<smiles>CCOC1CC(c2cccc3ccccc23)Nc2c(O)cccc21</smiles>

$74 \%$ yield; $d r>99 \cdot 1$ $91 \%$ ee<smiles>CC(C)(C)c1cccc(C(C)(C)C)n1</smiles>
DTBP

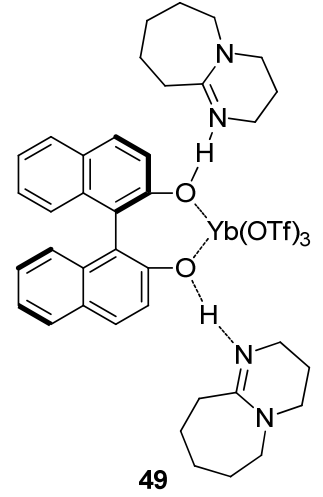

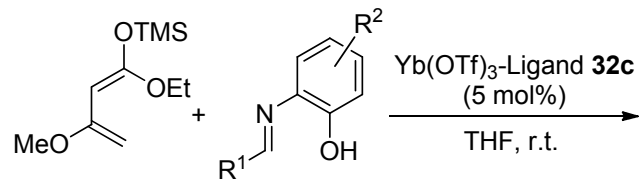

50

51 $\mathrm{R}^{1}=\operatorname{aryl}, \mathrm{R}^{2}=\mathrm{Me}$

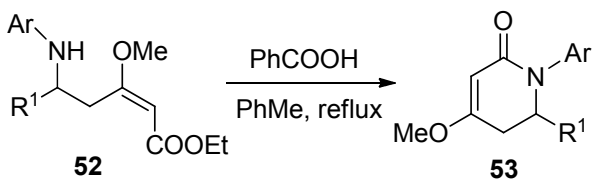

图式 6 Brassard 二烯 50 与醛亚胺 $\mathbf{5 1}$ 的氮杂 DA 反应 Scheme 6 The aza DA reaction of Brassard diene $\mathbf{5 0}$ and aldimine 51

对产物进行重结晶后，对映体过量值则高达 $99 \%$ ee. 由 于反应中间体 52 的存在，作者认为反应的环加成机理 是通过 Mannich 反应路径进行的 ${ }^{[44]}$. 在反应中, 底物 $\mathbf{5 0}$ 与 51 在 $\mathrm{Yb}(\mathrm{OTf})_{3}$-配体 32 配合物催化反应下，经 Mannich 反应生成中间体 $\mathbf{5 2}$, 最后再通过分子内成环得 到环加成产物 53.

2015 年, Wang 课题组 ${ }^{[45,46]}$ 在钎金属联荎酚磷酸酯 配合物 21d 的基础上，通过在分子结构内引入镧系金属 化合物 $\mathrm{Yb}(\mathrm{OTf})_{3}$, 形成新型手性双金属催化剂 $\mathrm{Yb}(\mathrm{OTf})_{3} / \mathrm{Y}[\mathrm{P}]_{3}(\mathbf{5 4})$ (Eq. 13).

Wang 等以 54 催化环己酮 $33, \beta, \gamma$-不饱和- $\alpha$-酮酸酯 29b 和对甲氧基苯胺 $(55)$ 的不对称三组分氮杂 DA 反应, 生成具有氮杂六元环的环加成产物 56 (Eq. 14). 研究发 现：当 $\mathrm{Yb}(\mathrm{OTf})_{3}$ 与钎金属联菜酚磷酸酯配合物 $\mathrm{Y}[\mathrm{P}]_{3}$ 以 


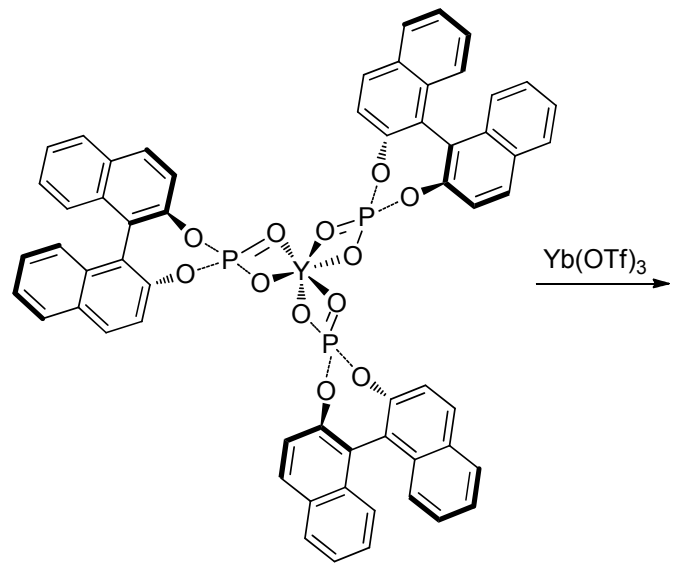

21d

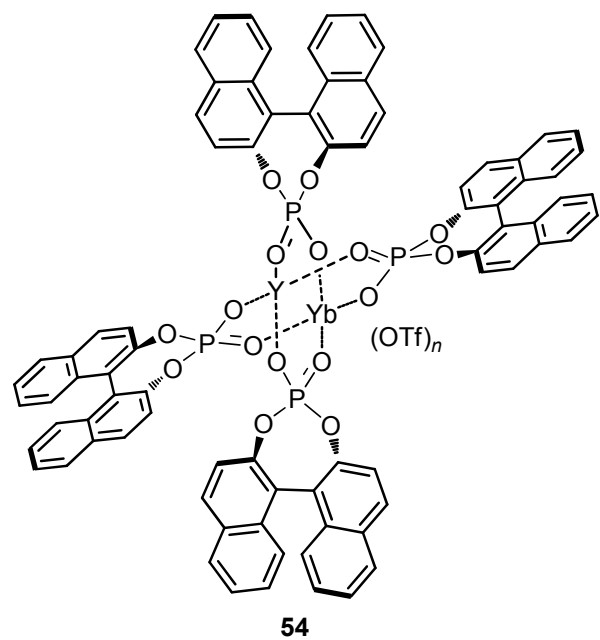<smiles>COc1ccc(N)cc1</smiles>

33

55

$29 b$<smiles>COc1ccc(N2C(C(=O)OCc3ccccc3)=C[C@H](c3ccc(Cl)cc3)C3=C2CCCC3)cc1</smiles><smiles>CC(C)OP(=O)([O-])Oc1ccc2ccccc2c1-c1c(OP)ccc2ccccc12</smiles>

$1: 1$ 配合时, 形成的 $\mathbf{5 4}$ 能成功地催化环加成反应进行, 反应产物的对映体过量值达 $91 \%$ ee , 产率为 $94 \%$. 在对 反应条件进行优化后发现, 溶剂的极性对反应的选择性 和产率均有影响. 使用极性小的溶剂能使反应获得更好 的实验结果.

\section{4 不对称分子内的 DA 反应}

分子内的 DA 反应在有机合成中有着重要的应用. 2013 年, Zakarian 课题组 ${ }^{[47]}$ 成功地合成了天然产物 Muironolide A. 为了进一步提高合成反应中关键步骤的 非对映选择性和对映选择性, 同年, Zakarian 等 ${ }^{[48]}$ 尝试 使用针系金属 La 催化分子内的 DA 反应，合成 Muironolide A 前体异吲哚啉酮 $\mathbf{5 8}$ (Eq. 15). 在反应中, 底物 57 会发生酮一烯醇互变异构, 随后与镧系金属 La 配位形 成 60, 再发生分子内的 DA 反应并获得环加成产物 61, 最后通过差向异构化而得到目标化合物 $\mathbf{5 8}$ (Scheme 7).

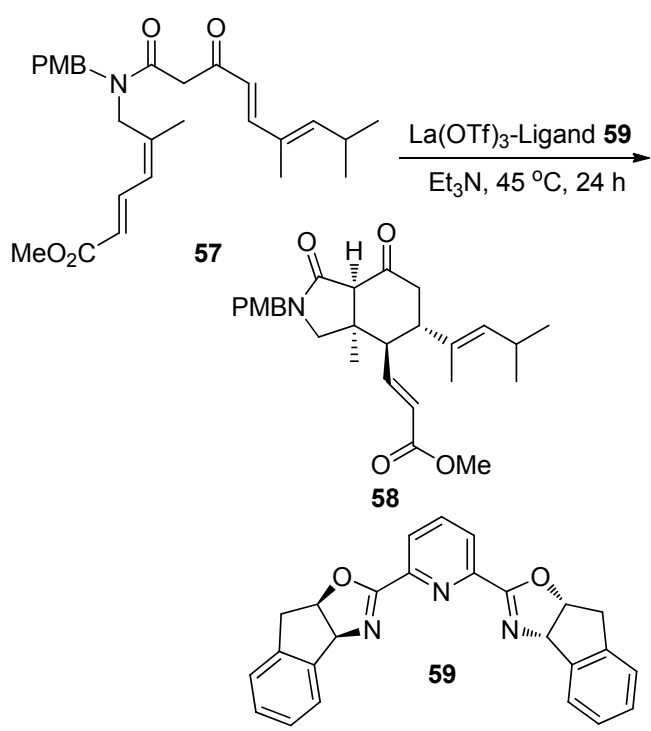

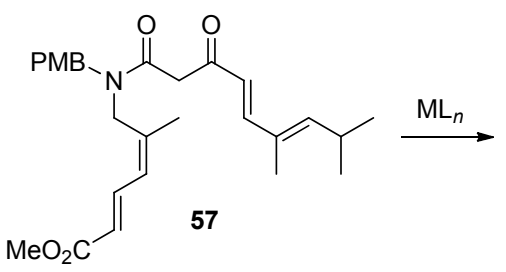

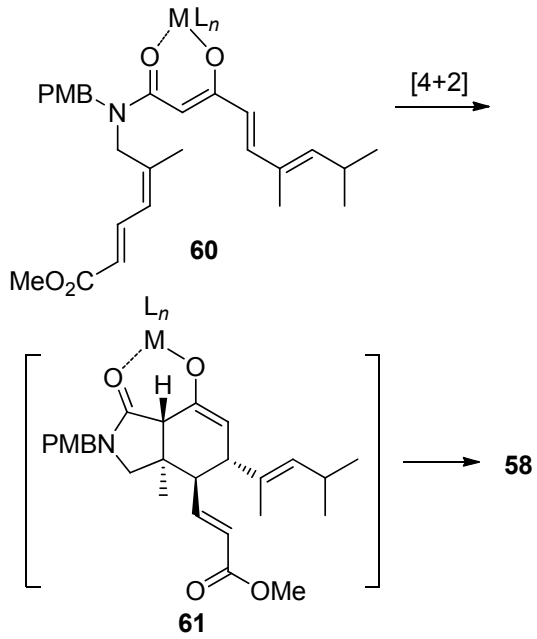

图式 7 金属催化的分子内 DA 反应

Scheme 7 Metal-catalyzed IMDA reaction 
研究发现镧系金属三氟甲磺酸盐 $\mathrm{La}(\mathrm{OTf})_{3}$ 能很好 地催化该 DA 反应进行, 而且反应具有很高的非对映选 择性 $(d r>20: 1)$, 产率为 $90 \%$. 为了实现反应的对映选 择性, Zakarian 等探索了不同手性配体与 $\mathrm{La}(\mathrm{OTf})_{3}$ 形成 的手性催化剂催化该反应进行, 可惜的是, 均没有获得 很好的对映选择性, 最好的结果是使用了配体 $\mathbf{5 9}$, 产物 的对映体过量值为 $43 \%$ ee.

$[3+2]$ 环加成反应能形成包括杂环戊烷衍生物在内 的五元环加成产物. 这类产物大多具有生物活性, 如 $\gamma$ 内酰胺和非天然氨基酸的中间体 ${ }^{[49,50]}$. 不对称的 [3+2] 环加成反应在天然产物的合成中更是起着十分重要的 作用. 近年来报道了不少关于镧系金属催化的不对称 $[3+2]$ 环加成反应, 研究针系金属催化不对称 $[3+2]$ 环 加成反应具有一定的科学意义和潜在的应用前景 ${ }^{[51]}$.

\section{1 氧化腈参与的不对称 $[3+2]$ 环加成反应}

氧化腈与碳碳双键的成环反应是合成异噁唑啉环 骨架结构单元的常用方法. 2007 年, Yamamoto 等 ${ }^{[52]}$ 尝试 使用 $\mathrm{Yb}(\mathrm{OTf})_{3}$ 与手性配体 PYBOX (4c) 形成的配合物催 化 $\alpha$-不饱和酮化合物 62 和苯甲酰氯肜 63 的 [3+2]环加 成反应, 生成异噁唑啉衍生物 64 (Eq. 16). 研究发现: 在不同的反应物 62 中, 杂环 $\mathrm{R}$ 上不带取代基的 62a 在 反应中能获得更高的对映选择性. 值得注意的是, 当反 应温度升高时, 反应的产率会随之下降. 作者认为 63 随 温度升高容易发生二聚, 从而导致反应的产率降低. 在 $35{ }^{\circ} \mathrm{C}$ 时, 62a 与 63 在 $\mathrm{Yb}(\mathrm{OTf})_{3}-\mathrm{PYBOX}(\mathbf{4 c})$ 催化下, 反 应产物的产率为 $35 \%$, 对映体过量值为 $69 \%$ ee .

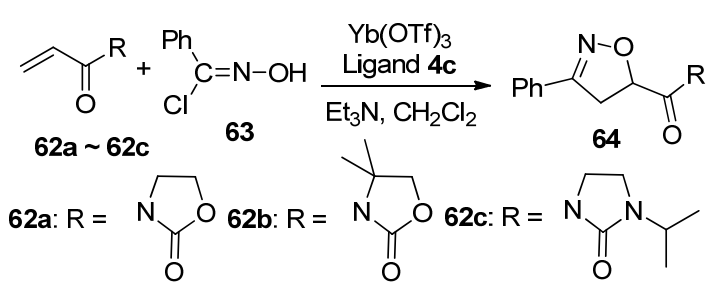

2008 年, Gucma 等 ${ }^{[33,54]}$ 报道了分别以 $(-)$-鹰爪豆碱 $[(-)$-Sparteine, 70]和 $(R)-$ BINOL (71) 作为手性配体, 并 与镧系金属三氟甲磺酸盐 $\mathrm{Yb}(\mathrm{OTf})_{3}$ 形成手性催化剂催 化烯烃与对三氟甲基苯甲腈 $N$-氧化物 66 的[3+2]环加 成反应, 生成相应的异噁唑啉衍生物(Eqs. 17, 18).

2011 年, Gucma 等 ${ }^{[55]}$ 又报道了以 $\mathrm{Yb}(\mathrm{OTf})_{3}$ 与不同的 手性配体形成的手性催化剂催化对三氟甲基苯甲腈 $N$ 氧化物 66 与丁烯酰胺 72 的环加成反应, 获得立体选择 性可控的异噁唑啉衍生物 73 (Eq. 19). 在探究不同的手 性配体对反应的影响后发现: 以(-)-Sparteine (70)、

\section{2 镧系金属催化不对称[3+2]环加成反应}
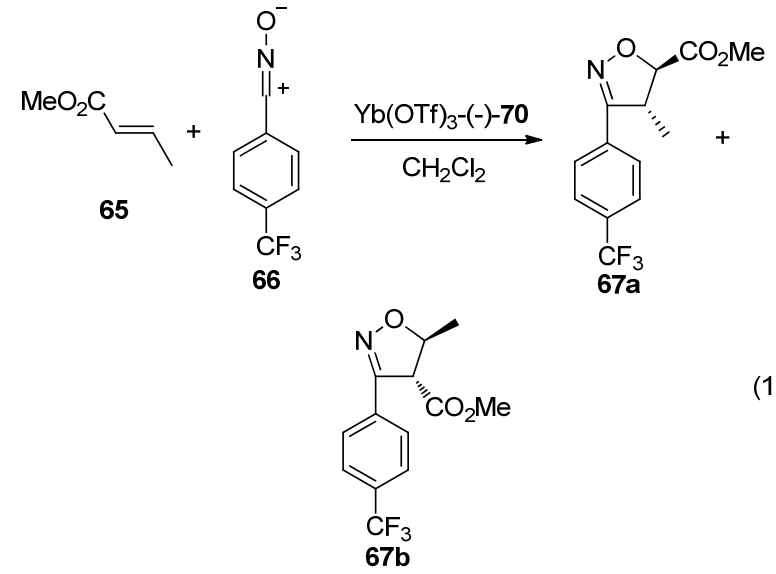

(17)

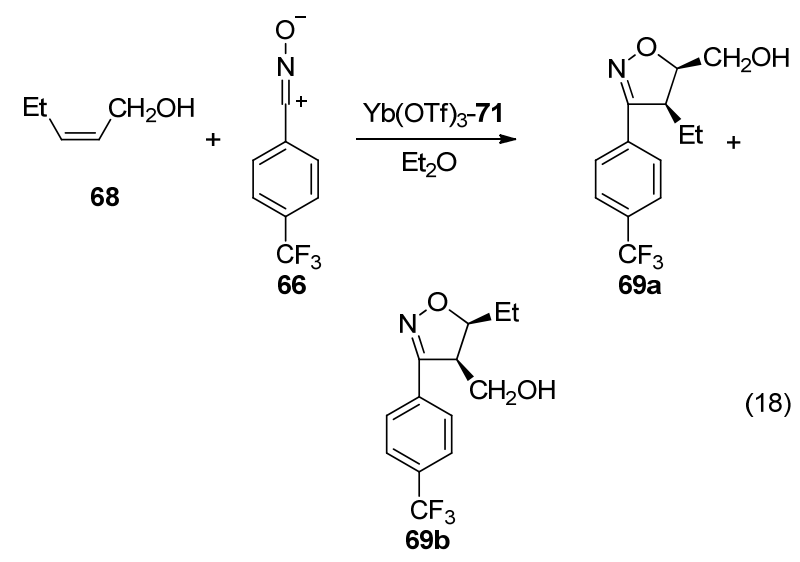

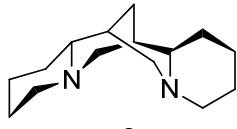

70

(-)-Sparteine<smiles>Oc1ccc2ccccc2c1-c1c(O)ccc2ccccc12</smiles>

71

(R)-BINOL

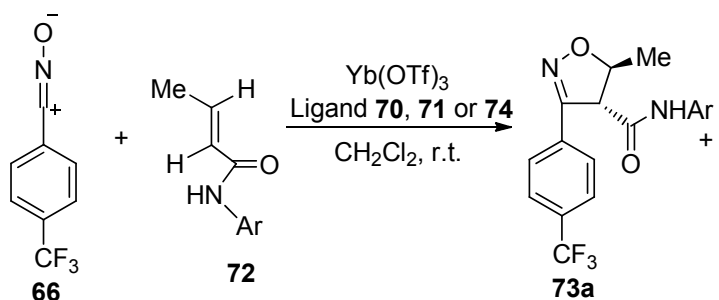<smiles>CCNC(=O)C1ON=C(c2ccc(C(F)(F)F)cc2)C1C</smiles>

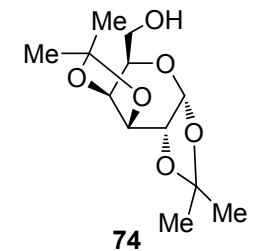

Chiral carbohydrate ligand 
$(R)$-BINOL (71) 和碳水化合物 74 作为手性配体的环加成 反应能获得良好的实验结果, 产物以 $73 \mathrm{~b}$ 构型为主, 对 映体过量值最高达 $99 \%$ ee ，具有很高的对映选择性.

基于对反应产物的立体构型和 Gucma 等应用 ESI-MS 跟踪测定和分析后, 提出了以 $\mathrm{Yb}(\mathrm{OTf})_{3}$ 与不同 配体催化下, 反应可能的手性诱导机理. 作者认为在 $\mathrm{Yb}(\mathrm{OTf})_{3}$ 与碳水化合物 74 催化反应中, 金属 $\mathrm{Yb}$ 与丁烯 酰胺 70 上的羰基氧相互配位, 使亲偶极体 70 更趋向于 从亚异丙基背面的 $R e$-face 进攻 66, 形成产物 76. 产物 的绝对构型可以通过用三异丁基嗍氢化锂还原成已知 的异噁唑啉甲醇衍生物 77 而确定, 为 $(4 R, 5 R)$ 构型 (Scheme 8). 对于生成的少量异构体 73a 的反应情况, 因为反应中缺少 $\mathrm{Yb}(\mathrm{OTf})_{3}$ 与 66 间配位连接的相互作用 而难以实现手性诱导, 这也解释了反应产物 73a 的 $e e$ 值 均很低的原因. 相反手性的产物可以通过 $\mathrm{Yb}(\mathrm{OTf})_{3}-(R)-$

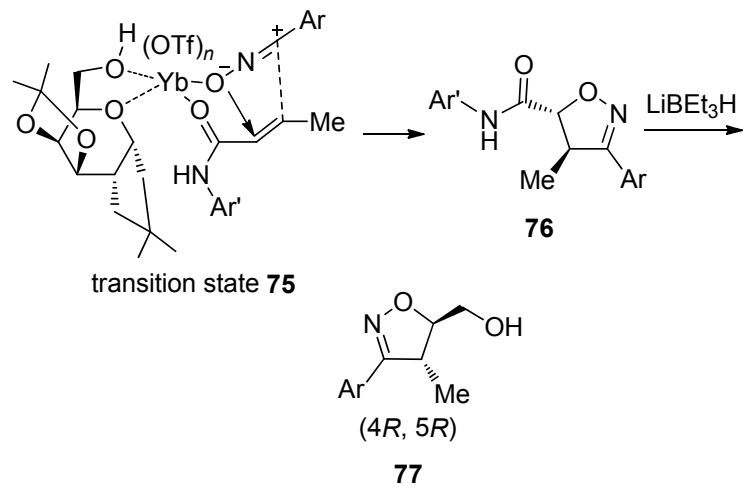

图式 $8 \mathrm{Yb}(\mathrm{OTf})_{3}$-碳水化合物 $\mathbf{7 4}$ 手性诱导的可能机理 Scheme 8 Proposed mechanism of chiral induction with the $\mathrm{Yb}(\mathrm{OTf})_{3}$-carbohydrate $\mathbf{7 4}$
BINOL 催化反应获得: 与前者相比，66 和 72 与金属中 心 $\mathrm{Yb}$ 配位的方式互换，亲偶极体 72 更利于从 $S i$-face 进攻 66, 形成( $4 S, 5 S)$ 构型产物 79 (Scheme 9).

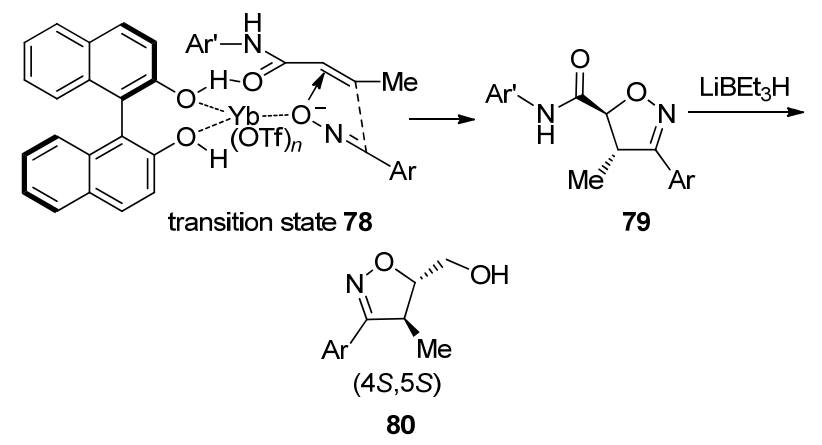

图式 $9 \mathrm{Yb}(\mathrm{OTf})_{3}-\mathrm{BINOL}$ 手性诱导的可能机理 Scheme 9 Proposed mechanism of chiral induction with the $\mathrm{Yb}(\mathrm{OTf})_{3}-(R)-\mathrm{BINOL}$

\section{2 羰基叶立德参与不对称 $[3+2]$ 环加成反应}

2005 年, Suga 课题组 ${ }^{[56]}$ 以 PYBOX 4c、4d 作为手性 配体，与 $\mathrm{Yb}(\mathrm{OTf})_{3}$ 和 $\mathrm{Sc}(\mathrm{OTf})_{3}$ 形成的配合物手性催化剂 催化羰基叶立德 82 与不同亲偶极体的[3+2]环加成反 应，生成环氧桥连多环化合物(Scheme 10). 研究发现， 在不同的反应条件下，反应均具有很好的对映选择性和 非对映选择性

在反应过程中，过渡金属 $\mathrm{Rh}$ 首先催化分解 86 上的 $\alpha$-重氮酮形成卡宾 ${ }^{[57,58]}$ ，随后卡宾进攻分子内羰基上的 氧形成羰基叶立德 $\mathbf{8 7}$, 并作为偶极体参与之后的 $[3+2]$ 环加成反应，生成环加成产物 88 (Scheme 11).

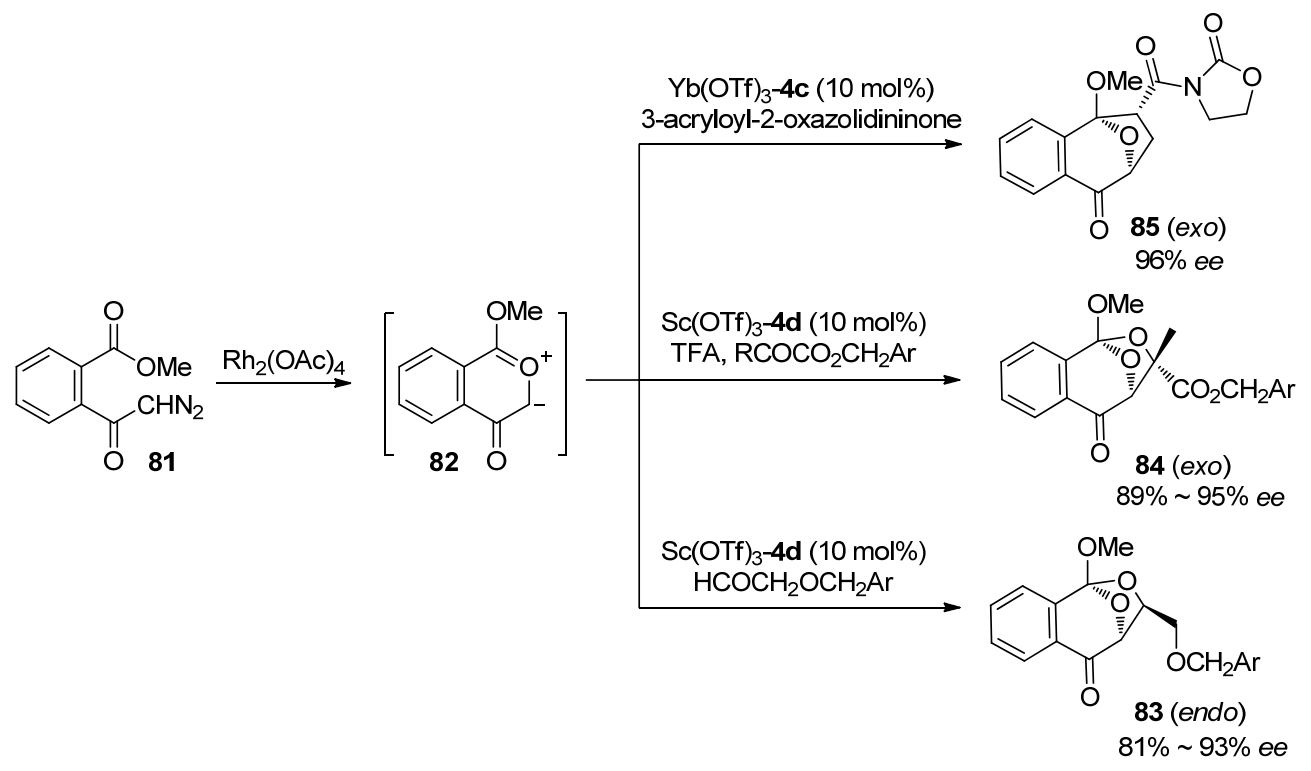

图式 10 羰基叶立德 82 在不同条件下的[3+2]环加成反应

Scheme $10 \quad[3+2]$ cycloaddition reaction of carbonyl ylide 82 in different condition 


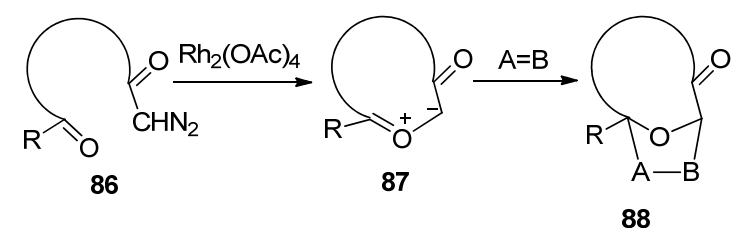

图式 11 卡宾-羰基的分子内环化与羰基叶立德的[3+2]环加 成的串联反应

Scheme 11 Tandem intramolecular carbenoid-carbonyl cyclization and 1,3-dipolar cycloaddition methodologies of carbonyl ylides

2007 年, Suga 课题组 ${ }^{[59]}$ 报道了以 $\mathrm{Eu}(\mathrm{OTf})_{3}-\mathrm{PYBOX}$ (4e)配合物催化羰基叶立德 82 与环己基乙烯基醚发生 反电子需求的偶极体-LUMO/亲偶极体-HOMO 控制的 环加成反应, 生成环氧桥连多环化合物 89 (Scheme 12). 作者认为可能是由于环己基乙烯基醚中的氧原子与 $\mathrm{C}=$ $\mathrm{C}$ 键发生 $\mathrm{p}-\pi$ 共轭, 增加 $\mathrm{C}=\mathrm{C}$ 键的电子云密度, 致使成 环反应以偶极-HOMO/亲偶极-LUMO 控制方式进行. 反应产物的产率为 $99 \%$, 对映体过量值高达 $96 \%$ ee.

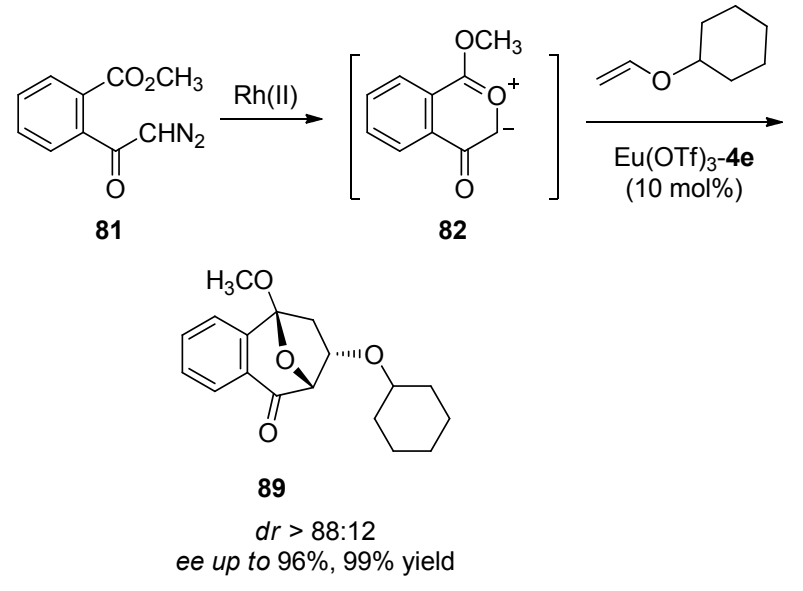

图式 12 羊基叶立德 82 的环加成反应

Scheme 12 Cycloaddition reaction of carbonyl ylide 82

Suga 课题组 ${ }^{[60]}$ 通过进一步研究, 2010 年报道了以 $\mathrm{Ln}(\mathrm{OTf})_{3}$-PYBOX (4e) $(\mathrm{Ln}=\mathrm{Eu}, \mathrm{Ho}, \mathrm{Gd}, \mathrm{Tm}, \mathrm{Lu})$ 镧系金 属手性催化剂催化羰基叶立德 91 与丁基乙烯基醚的 [3 +2 ]环加成反应, 生成环加成产物 92 (Scheme 13). 研究 发现: 在不同镧系金属化合物中, $\mathrm{Lu}(\mathrm{OTf})_{3}$ 与配体 $\mathbf{4 e}$ 形 成的催化剂在以二氯甲烷作为溶剂和甲醇作为添加剂 的条件下, 催化该反应能获得最好的实验结果. 反应生 成 exo 构型产物 92, 产率为 73\%, 对映体过量值为 $82 \%$ $e e$. 值得注意的是, 在反应中增加催化剂的用量反而会 降低反应的对映选择性.

根据产物立体构型的专一性, 作者认为 $\operatorname{Ln}(\mathrm{OTf})_{3}$ PYBOX (4e)配合物在空间中形成的空间位阻是反应生

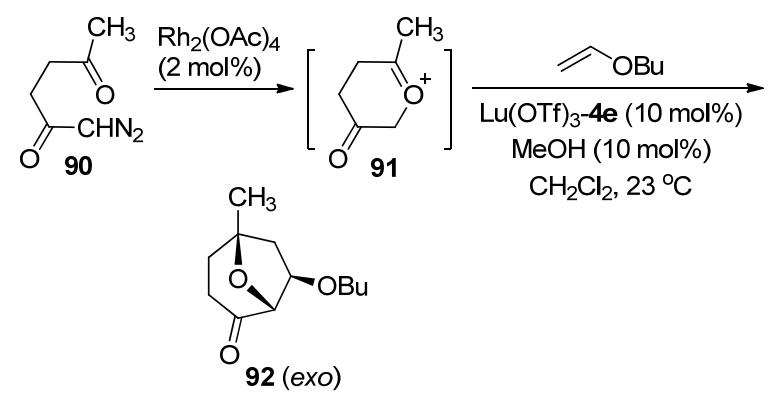

图式 13 羰基叶立德 91 的环加成反应

Scheme 13 Cycloaddition reaction of carbonyl ylide 91

成的产物具有高立体选择性的主要原因，在反应中，配 合物的金属中心 $\operatorname{Ln}$ 能与羰基叶立德 91 配位. 而由于配 体 $4 \mathrm{e}$ 在空间中的不对称排布，在 91 上方形成的空间位 阻起到保护作用，阻碍了亲偶极体的从上方进攻，而更 有利于从下方进攻, 得到 exo 构型的产物 92 (Scheme 14).

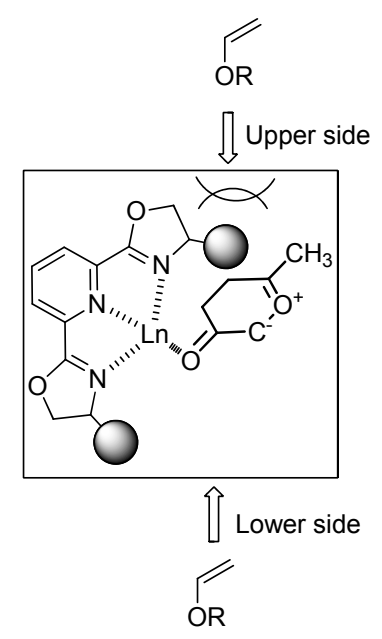

图式 14 反应不对称诱导的可能机理

Scheme 14 Proposed mechanism for asymmetric induction in the reaction

2013 年, Suga 课题组 ${ }^{[61]}$ 又报道了以 $\operatorname{Ln}(\mathrm{OTf})_{3^{-}}$ PYBOX (4e) $(\mathrm{Ln}=\mathrm{Lu}, \mathrm{La}, \mathrm{Tm})$ 镧系金属配合物作为手 性催化剂, 催化由具有不同杂环分子数的 $N$-重氮乙酰 基内酰胺 93, 通过过渡金属 $\mathrm{Rh}$ 催化形成的羰基叶立德 94 与 $\alpha, \beta$-不饱和 $N$-酰基噁唑烷酮 1 的[3+2]环加成反应, 生成相应的多环化合物 95 (Scheme 15). 研究发现: 在 $\mathrm{La}(\mathrm{OTf})_{3}-\mathrm{PYBOX}(\mathbf{4 e})$ 催化的反应中，虽然底物 1 中不同 的取代基 $\mathrm{R}$ 对反应的产率和非对映选择性的影响，但是 反应均具有很好的对映选择性，对映体过量值最高可达 $95 \% e e$, 而且能实现反应物的完全转化. 在相似的反应 条件下, 改变羰基叶立德 94 碳环数 $n$ 和 1 中的 $\mathrm{R}$ 取代 基，反应仍具有良好的立体选择性(Scheme 16). 


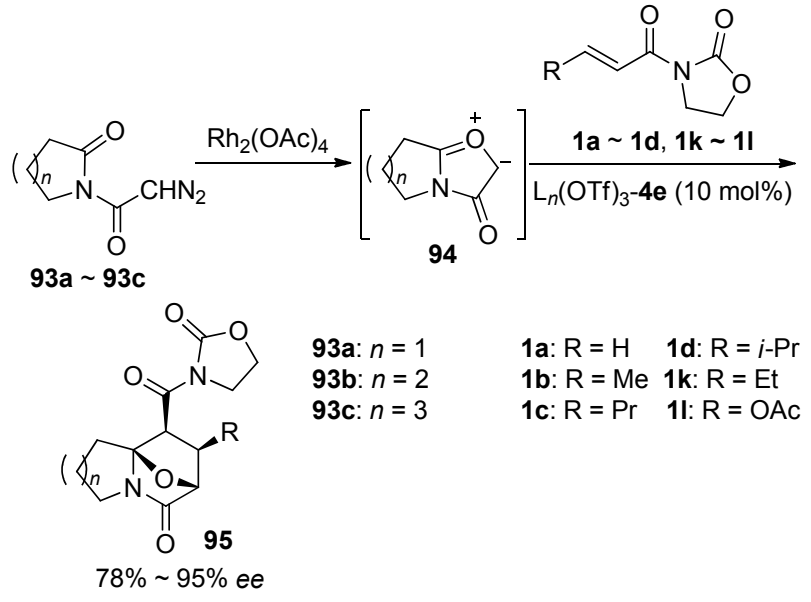

图式 15 羰基叶立德 94 的环加成反应

Scheme 15 Cycloaddition reaction of carbonyl ylide 94<smiles>CC1C(=O)N2CCCC23OC1[C@@H]3C(=O)N1CCOC1=O</smiles><smiles>CN1CCCC2OC1C[C@H]2C(=O)N1CCOC1=O</smiles><smiles>CC1C(=O)N2CCCCC23OC1[C@@H]3C(=O)N1CCOC1=O</smiles>

$\mathrm{La}(\mathrm{OTf})_{3}:$ quant yield Lu(OTf $)_{3}: 55 \%$ yield $\mathrm{La}(\mathrm{OTf})_{3}: 78 \%$ yield exo/endo $=75 / 25$ exolendo $=79 / 21 \quad$ exolendo $=85 / 15$ $95 \%$ ee $(e x o)$ $87 \%$ ee (exo) $87 \%$ ee (exo)<smiles>CCC1C(=O)N2CCCCC12C(=O)N1CCOC1=O</smiles>

$\mathrm{La}(\mathrm{OTf})_{3}: 68 \%$ yield exolendo $=87 / 13$ $86 \%$ ee (exo)<smiles>O=C1CCCCC2OC1C[C@H]2C(=O)N1CCOC1=O</smiles>

$\operatorname{Tm}(\mathrm{OTf})_{3}: 53 \%$ yield exolendo $=93 / 7$ $85 \%$ ee $($ exo $)$
图式 16 不同的羰基叶立德 94 在不同条件下的 $[3+2]$ 环加成 反应

Scheme $16[3+2]$ cycloaddition reaction of different carbonyl ylide 94 in different condition

2014 年, 冯小明课题组 ${ }^{[62]}$ 发现镧系金属 Gd 与 $N, N^{\prime}$ 二氧化物配体 32c 形成 $\mathrm{Gd}(\mathrm{OTf})_{3}-32 \mathrm{c}$ 催化剂, 可以有效 催化 1-苯基-2,2-二苯甲酰基环氧乙烷(96)开环形成羰基 叶立德中间体 97, 97 再与苯甲酫 19 进行 [3+2] 环加成反 应生成 cis-1,3-二氧戊烷衍生物 98 (Scheme 17). 反应不 仅具有很高的对映选择性和非对映选择性 $(90 \% e e, d r>$ $95: 5$ ), 而且反应产物的产率为 $92 \%$. 研究发现, 添加 剂双三氟甲基磺酰亚胺锂 $\left(\mathrm{LiNTf}_{2}\right)$ 的加入, 能使反应的 产率大幅提高.

通过对产物绝对构型和镧系金属亲氧特性的分析, 冯小明等提出反应中可能的过渡态模型(Scheme 18).

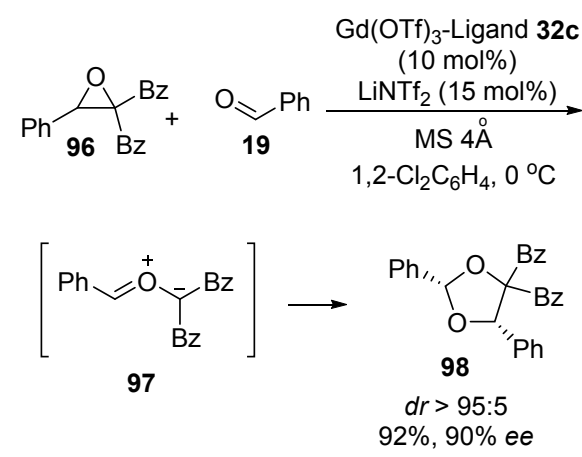

图式 17 羰基叶立德 97 的环加成反应

Scheme 17 Cycloaddition reaction of carbonyl ylide 97

首先, $\mathrm{Gd}(\mathrm{OTf})_{3}$ 与配体 $\mathbf{3 2 c}$ 中的氧形成四配位的结构. 随后 96 中的 $\mathrm{C}=\mathrm{O}$ 基团与 $\mathrm{Gd}$ 配位，在形成空间中六配 位结构的同时, 96 转变成羰基叶立德 97 . 由于配体 32c 中二异丙基苯基的空间位阻, 苯甲醛 19 更倾向于从 $R e$-face 进攻而得到环加成产物 98 (Scheme 18).

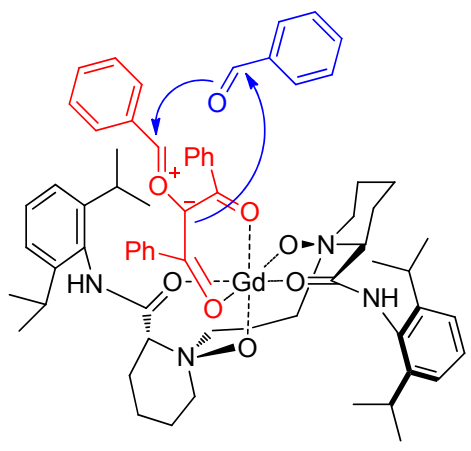

图式 $18 \mathrm{Gd}$ 催化不对称[3+2]环加成可能的过渡态模型 Scheme 18 Proposed transition-state model of $\mathrm{Gd}$ catalyze asymmetric $[3+2]$ cycloaddition

\section{3 硝酮参与的不对称 $[3+2]$ 环加成反应}

早在 1998 年, Kobayashi 等 ${ }^{[63]}$ 就报道了在手性配体 BINOL (73)和三级胺的作用下, 针系金属 $\mathrm{Yb}(\mathrm{III})$ 不对称 催化异噁唑衍生物的 $[3+2]$ 环加成反应.

2006 年, Evans 等 ${ }^{[64]}$ 报道了以 $\mathrm{Ce}(\mathrm{OTf})_{4}-\mathrm{PYBOX}$ 配 合物 102 催化 2-酰基咪唑 99 和硝酮 100 的 [3+2]不对称 环加成反应, 制备异噁唑衍生物 101 (Eq. 20). 研究发 现: 在乙酸作为溶剂的条件下, 反应能够实现很好的对 映选择性，产物的对映体过量值为 $99 \% e e$ ，而且产率高 达 $97 \%$. 虽然在不同价态的锞系金属 $\mathrm{Ce}$ 中, $\mathrm{Ce}(\mathrm{III})$ 与 $\mathrm{Ce}(\mathrm{IV})$ 催化该反应均具有很好的产率和对映选择性, 但 是当 99 中的取代基 $\mathrm{R}$ 换成芐基等位阻大的取代基时, 底物难以进攻, 在这种情况下, $\mathrm{Ce}(\mathrm{IV})$ 与 $\mathrm{Ce}(\mathrm{III})$ 相比体 现出更好的反应活性. 值得注意的是, 反应中痕量的水 分会降低环加成反应的立体选择性. 

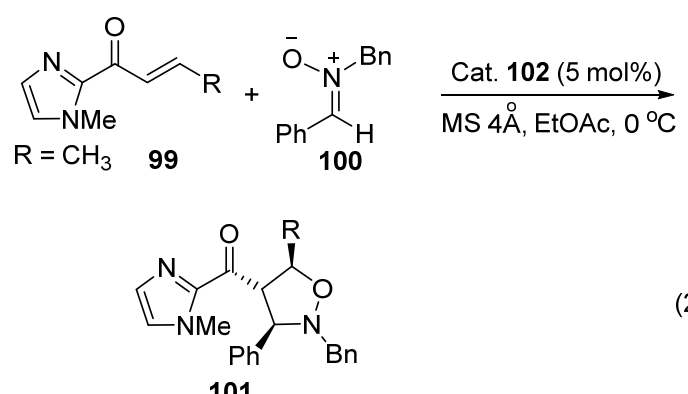

101

ee up to $99 \%$

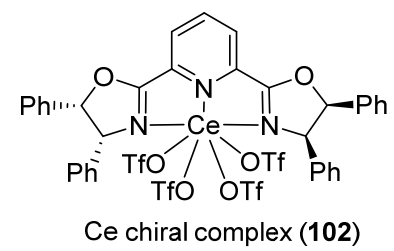

\section{4 其他 1,3 偶极体参与的[3+2] 环加成反应}

噁唑烷酮化合物是一种重要的新型抗菌化合物, 在 生物医药中有着重要的应用. 2010 年, Barros 等 ${ }^{[65]}$ 报道 了通过镧系金属氯化物 $\mathrm{YbCl}_{3}$ 催化环氧磷酸二乙酯 103 与异氭酸酯 104 的 $[3+2]$ 环加成反应(Eq. 21), 生成啞唑 烷酮化合物 $\mathbf{1 0 6 .}$

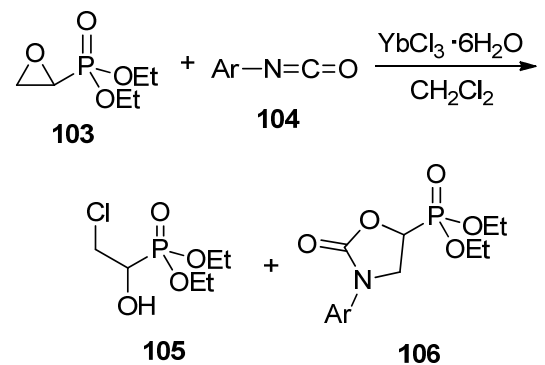

Barros 等研究发现: 与其他金属化合物相比, $\mathrm{YbCl}_{3}$ 在催化 103 与 104 环加成反应中, 反应活性最好, 且具 有很好的区域选择性, 而且反应中使用水合三氯化镱 $\left(\mathrm{YbCl}_{3} \cdot 6 \mathrm{H}_{2} \mathrm{O}\right)$ 能进一步提高该反应的反应速率 ${ }^{[66]}$, 但是 $\mathrm{Yb}(\mathrm{OTf})_{3}$ 在反应中并不具备催化活性. 作者认为可能反 应的机理是: 首先氯化物 $\left(\mathrm{YbCl}_{3}\right)$ 参与 103 开环形成 1,2烷氧基氯化物, 随后再与 104 发生 $[3+2]$ 环加成反应生 成 106. 产物中含有氯醇化合物 105 也与上述机理描述 相一致, 而且环氧化合物与金属的配位能促进这一过程 的进行. Barros 等在篎选不同的手性配体后发现: 当使 用 PYBOX (4c)作为手性配体, 产物的对映体过量值最 高可达 $75 \%$ ee, 反应产物的产率为 $63 \%$. 而使用对位取 代有强给电子基团的芳基异氭酸酯作为反应物时, 特别 是当取代基为甲氧基，反应的区域选择性会降低(106： $107=2.5: 1)$ (Eq. 22).

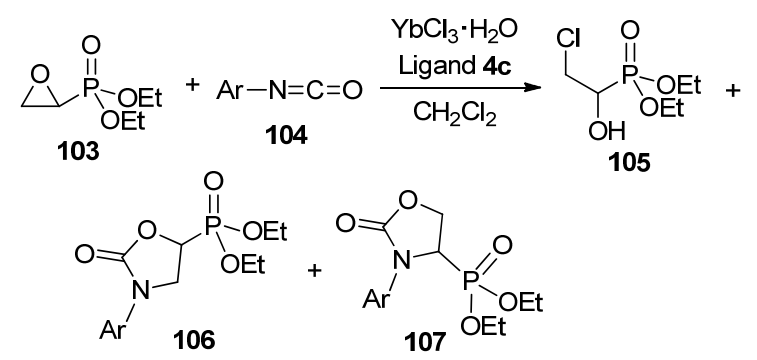

\section{3 镧系金属催化不对称[2+2]环加成反应}

有关镧系金属催化 $[2+2]$ 环加成反应的相关报道并 不多, 且不对称催化 $[2+2]$ 环加成反应在近几十年中才 有相关报道 ${ }^{[67 ~ 69]}$. 这里主要介绍通过镧系金属催化烯 醇式化合物与亚胺、醛类化合物的不对称 $[2+2]$ 环加成 反应.

2002 年, Lectka 课题组 ${ }^{[70]}$ 使用非手性的金属三氟甲 磺酸盐 $\mathrm{M}(\mathrm{OTf})_{3}(\mathrm{M}=\mathrm{La}, \mathrm{Al}, \mathrm{Sc}, \mathrm{In})$ 和手性的亲核试剂苯 甲酰喹啉 111 形成的双功能催化剂, 催化苯乙酰氯 $108 \mathrm{a}$ 与亚胺酯 109 的不对称 $[2+2]$ 环加成反应, 生成 $\beta$-内酰 胺 110 (Eq. 23). 但是镧系金属 La 与其他金属(如 In)相 比, 与手性的亲核试剂 111 形成的双功能催化剂催化反 应的产率较低(63\%).
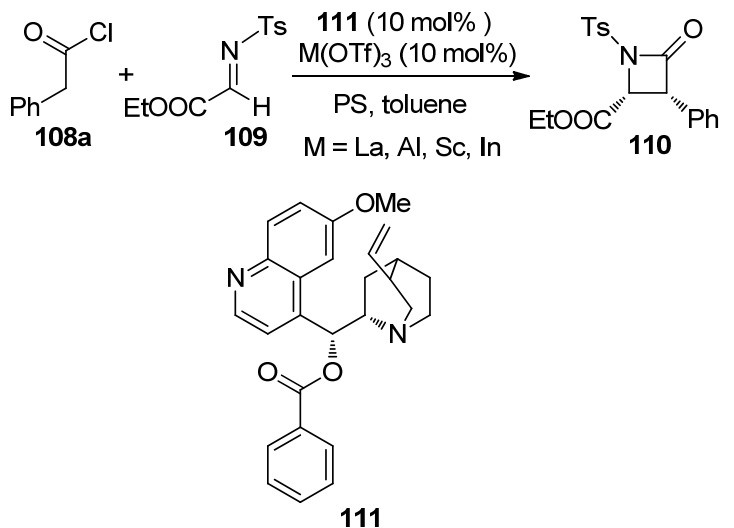

2005 年, Calter 课题组 ${ }^{[71]}$ 报道了以 $\operatorname{Er}(\mathrm{OTf})_{3}$ 和硅基 金鸡纳生物碱(122，简称 TMSQD)形成的双功能催化剂 催化酰氯 108 和芳基甲醛 112 的[2+2]环加成反应, 生 成 $\beta$-内酯化合物 113 (Eq. 24). 研究发现反应中产物具有 很好的对映选择性，对映体过量值高达 99\% ee.

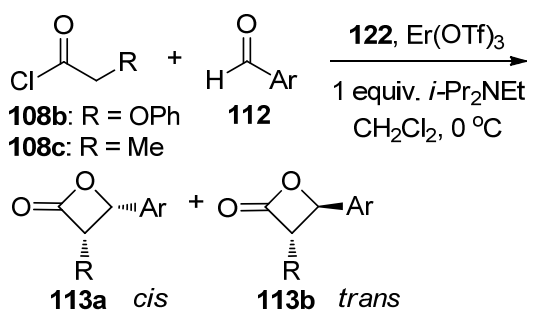

研究发现，酰氯上不同的取代基对反应产物的构型 有着很大的影响，当取代基 $\mathrm{R}^{1}$ 为甲基时，产物构型以 
trans 构型为主. 作者认为 $\operatorname{Er}(\mathrm{OTf})_{3}$ 易于分别与羰基和烯 醇上的氧配位形成开放的过渡态 115 , 而不是配位形成 紧密的过渡态 116. 随着 $\operatorname{Er}(\mathrm{OTf})_{3}$ 使用量的增加, 所得 产物 trans 构型比例增加也同样说明了这一机理(Scheme 19). 当取代基 $\mathrm{R}^{1}$ 为苯氧基时，由于金属中心在反应中 能与烯醇结构中的苯氧基和烯醇上的氧同时配位形成 117 配位结构, 且由于 112 中芳香基团 $\left(\mathrm{R}^{2}\right)$ 空间位阻的影 响, 更有利于形成过渡态 $\mathbf{1 1 9}$, 进而获得 $c i s$ 构型产物 (Scheme 20).

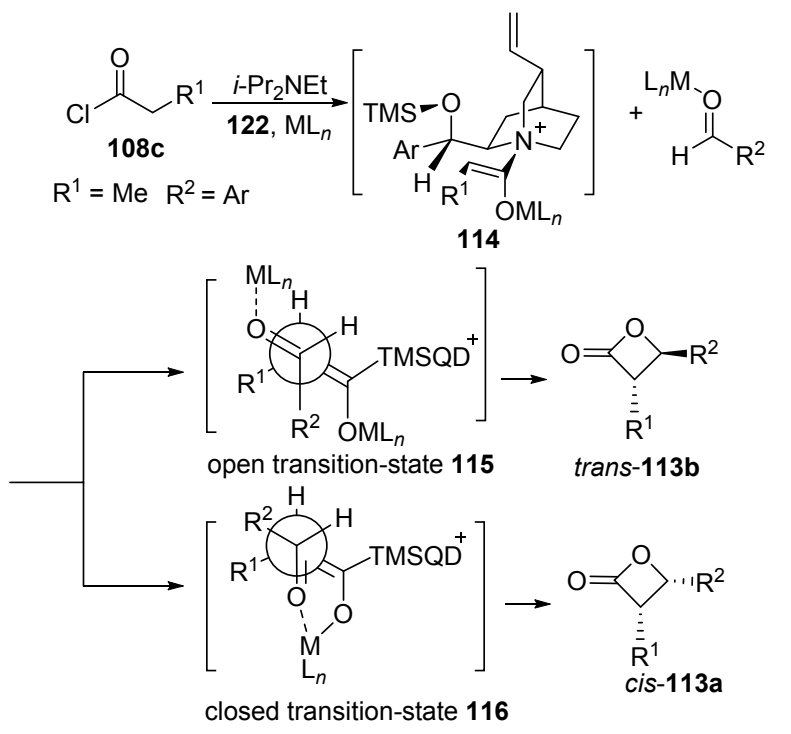

图式 19 烷基酰氯在双功能催化剂中可能的反应机理 Scheme 19 Plausible mechanism for alkyl chloride by bifunctional catalysis
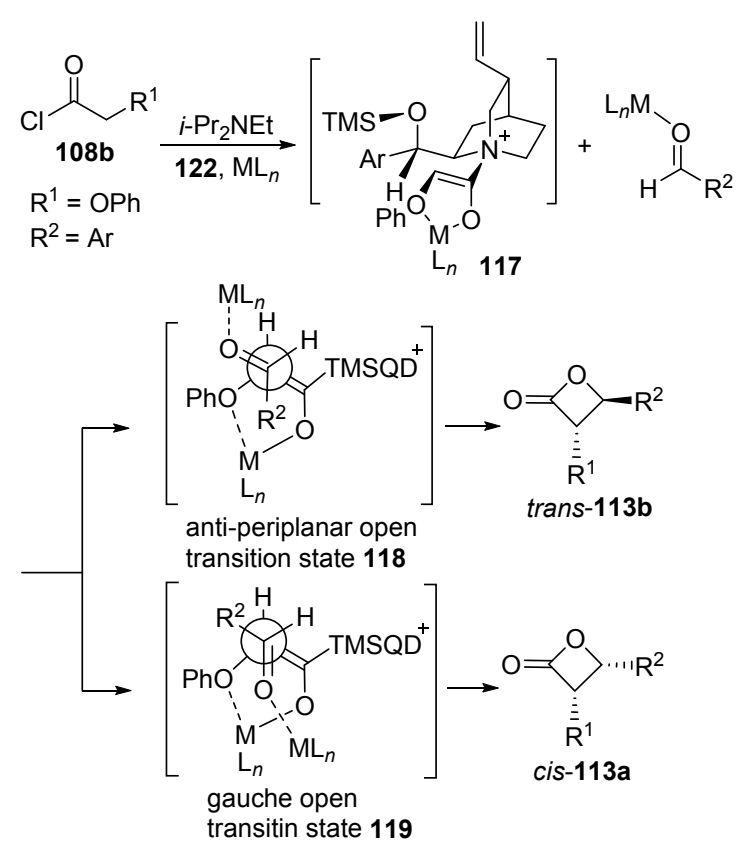

图式 20 苯氧酰氯在双功能催化剂中可能的反应机理 Scheme 20 Plausible mechanism for alkoxycarbonyl chloride by bifunctional catalysis
2007 年, Calter 课题组 ${ }^{[72]}$ 又报道以硅基金鸡纳生物 碱 122 和双三甲基硅基胺基稀土金属化合物 $\mathrm{M}\left(\mathrm{N}(\mathrm{TMS})_{2}\right)_{3}(\mathrm{M}=\mathrm{Nb}, \mathrm{Yb}, \mathrm{Sc}, \mathrm{Y})$ 形成催化剂催化苯氧 基乙酰氯 $108 \mathrm{~b}$ 和亚胺 120 的 [2+2]环加成反应, 生成 $\beta$ 内酰胺 121 (Eq. 25). Calter 等在用不同的金属中心催化 反应后发现: 当金属中心为 $\mathrm{Yb}$ 时，反应具有最高的产 率和对映体过量值(产率为 $83 \%$, ee 值为 $94 \%$ ), 产物以 cis 构型为主.

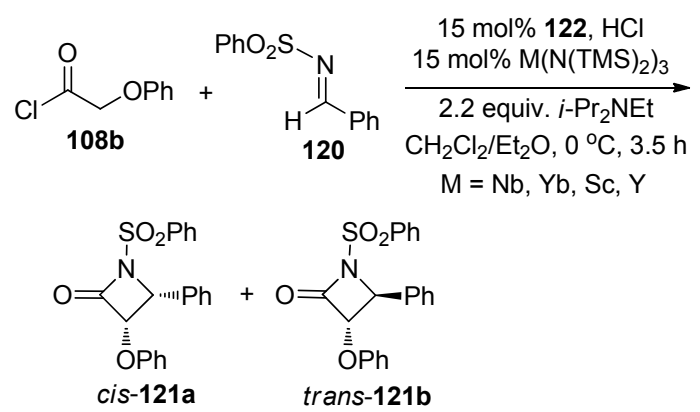<smiles>C=CC1CN2CCC1N2[C](OC(C)C)c1ccnc2ccc(OC)cc12</smiles>

根据产物的构型, Calter 等提出了可能的反应机理 (Scheme 21). 金属中心在反应中与 $\mathbf{1 0 8 b}$ 烯醇结构中的 苯氧基和烯醇上的氧同时配位，且由于 $\mathbf{1 2 0}$ 中的 $\mathrm{N}$ 原子 上的磺酰基强吸电子作用和大的空间位阻，使 $\mathrm{N}$ 原子不 可能与金属形成配位，倾向于形成开放的空间结构. 对 于反应中可能存在的两种过渡态，由于在过渡态 123 中, 120 中的苯基与 $\mathrm{M}\left(\mathrm{N}(\mathrm{TMS})_{2}\right)_{3}$ 间存在空间位阻的相互影 响, 这一过渡态并不稳定, 所以反应物更倾向于形成过 渡态 124, 产物以 cis 构型为主.

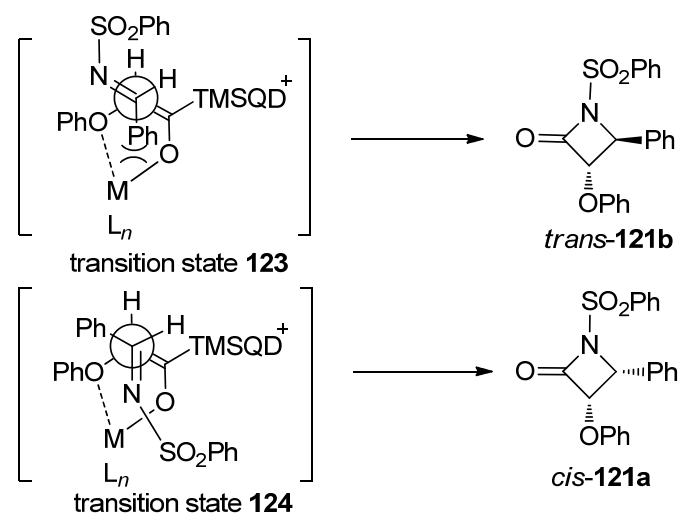

图式 21 合成不同构型的 $\beta$-内酰胺 121 可能反应机理 Scheme 21 Plausible mechanism for different configuration of $\beta$-lactone 121 


\section{4 镧系金属催化不对称[2+1]环加成反应}

$[2+1]$ 环加成反应可以形成三元环化合物. 2007 年, Shibasaki 课题组 ${ }^{[73]}$ 报道了首例催化量的 Lewis 酸催化的 苯乙烯基-(1-吡咯)甲酮(125)与硫叶立德 126 的不对称 $[2+1]$ 环加成反应, 生成 $(S, S)$-2-苯基环丙基-(1-吡咯)甲 酮 127 (Eq. 26). 镧系金属 $\mathrm{La}$ 和金属 $\mathrm{Li}$ 与手性配体 $(S)-$ 二羟基联苯(128)形成的杂双金属催化剂 $(S)-\mathrm{La}-\mathrm{Li}_{3}$ (biphenyldioate) 3 (129), NaI 作为添加剂, 催化该不对称 $[2+1]$ 环加成反应, 表明具有很高的反应活性, 反应产 率为 $96 \%$, 对映体过量值高达 $99 \%$ ee. 研究表明, 添加 剂 $\mathrm{NaI}$ 的使用是反应成功转化的关键. $\mathrm{NaI}$ 的加入使得 催化剂 129 中的 $\mathrm{Li}$ 与 $\mathrm{Na}$ 发生置换, 改变了反应中的不 对称环境, 从而导致了反应对映选择性的提高.
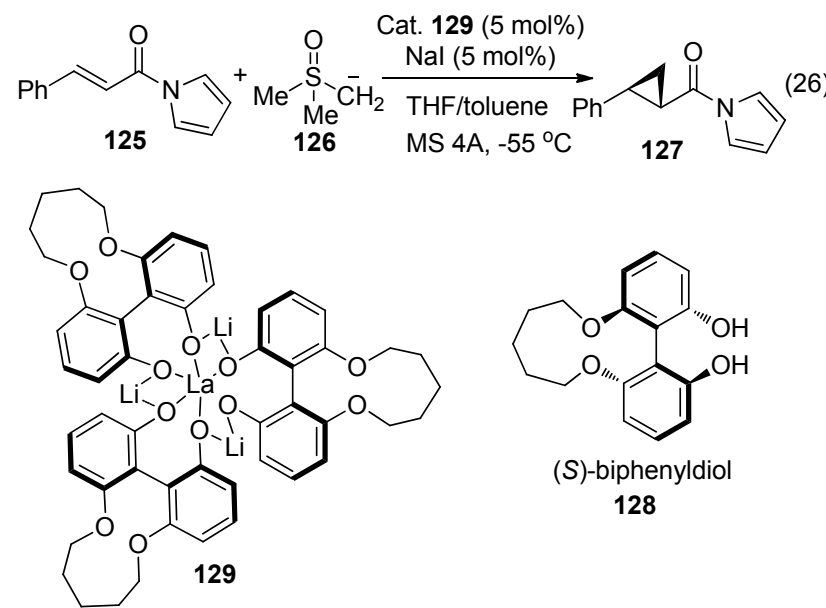

128

(S)-La-Li ${ }_{3}$-(biphenyldioate) $)_{3}$

\section{5 结论与展望}

环加成反应是合成单环及多环化合物的一类非常 直接有效的方法. 镧系金属催化不对称 $[4+2] 、[3+2]$ 、 $[2+2]$ 和 $[2+1]$ 等环加成反应, 为合成不同的环状手性 化合物提供了更多的方法和手段. 而且镧系金属催化不 对称环加成反应中展现出良好的立体选择性和催化活 性, 与传统的过渡金属相比, 在水相中具有稳定性和催 化剂可回收性, 大大提高了经济和环境效益. 但是, 镧 系金属催化应用的范围较小, 催化剂的用量也相对较 多. 因此, 发展高催化活性、高对映选择性的镧系金属 配合物等催化剂及其在其他类型的环加成反应中的应 用仍然是将来需要研究的重点课题.

\section{References}

[1] Qian, C.-T.; Wang, C.-H.; Chen, Y.-F. Acta Chim. Sinica 2014, 72, 883 (in Chinese).

(钱长涛, 王春红, 陈耀峰, 化学学报, 2014, 72, 883.)

[2] Qian, C.-T.; Du, C.-P. Organolanthanide Chemistry, Chemical Industry Press, Beijing, 2004 (in Chinese).
(钱长涛, 杜灿屏, 稀土金属有机化学, 化学工业出版社, 北京, 2004.)

[3] Averill, D. J.; Allen, M. J. Catal. Sci. Technol. 2014, 4, 4129.

[4] Kumagai, N.; Shibasaki, M. Angew. Chem., Int. Ed. 2013, 52, 223.

[5] Edelmann, F. T. Coord. Chem. Rev. 2014, 261, 73.

[6] Ward, B. D.; Gade, L. H. Chem. Commun. 2012, 48, 10587.

[7] Jia, Y.; Fan, M.; Chen, H.-N.; Miao, Y.-T.; Xing, L.; Jiang, B.-H.; Cheng, Q.-F.; Liu, D.-W.; Bao, W.-K.; Qian, B.; Wang, J.-L.; Xing, X.-D.; Tan, H.-P.; Ling, Z.-H.; Chen, Y. J. Colloid Interface Sci. 2015, 458, 293.

[8] Kotha, S.; Deodhar, D.; Khedkar, P. Org. Biomol. Chem. 2014, 12, 9054.

[9] Juhl, M.; Tanner, D. Chem. Soc. Rev. 2009, 38, 2983.

[10] Healy, A. R.; Westwood, N. J. Org. Biomol. Chem. 2015, 13, 10527.

[11] Smith, L. K.; Baxendale, L. R. Org. Biomol. Chem. 2015, 13, 9907.

[12] Takao, K. I.; Munakata, R.; Tadano, K. I. Chem. Rev. 2005, 105, 4779.

[13] Bednarski, M.; Damishotsky, S. J. Am. Chem. Soc. 1983, 105, 3716.

[14] Bednarski, M.; Maring, C.; Damishotsky, S. Tetrahedron Lett. 1983, 24, 3451.

[15] Luo, R.-S.; Yang, D.-Q. Chin. J. Org. Chem. 2007, 27, 958 (in Chinese).

(罗人仕, 杨定乔, 有机化学, 2007, 27, 958.)

[16] Hu, P.; Long, Y.-H.; Wang, H.; Mo, H.-H. Chin. J. Org. Chem. 2008, 28, 1181 (in Chinese).

(胡萍, 龙玉华, 王辉, 莫海洪, 杨定乔, 有机化学, 2008, 28, 1181.)

[17] Bian, H.-X.; Yang, D.-Q. Chin. J. Org. Chem. 2010, 30, 506 (in Chinese). (边红旭, 杨定乔, 有机化学, 2010, 30, 506.)

[18] Duan, Z.-B.; Long, Y.-H.; Yang, D.-Q. Chin. J. Org. Chem. 2010, 30, 368 (in Chinese).

(段泽斌，龙玉华，杨定乔，有机化学，2010，30, 368.)

[19] Zeng, Z.-Y.; Yang, D.-Q. Chin. J. Org. Chem. 2013, 33, 2131 (in Chinese).

(曾中一, 杨定乔, 有机化学, 2013, 33, 2131.)

[20] Cheng, G.; Yang, D.-Q. Chin. J. Org. Chem. 2015, 35, 2023 (in Chinese).

(程果，杨定乔，有机化学，2015, 35, 2023.)

[21] (a) Furuta, K.; Miwa, Y.; Iwanaga, K.; Yamamoto, H. J. Am. Chem. Soc. 1988, 110, 6254.

(b) Chapuis, C.; Jurczak, J. Helv. Chim. Acta 1987, 70, 436.

(c) Narasaka, K.; Inoue, M.; Okada, N. Chem. Lett. 1986, 1109.

(d) Maruoka, K.; Itoh, T.; Shirasaka, T.; Yamamoto, H. J. Am. Chem. Soc. 1988, 110, 310.

(e) Oppolzer, W. Angew. Chem., Int. Ed. 1984, 23, 876.

[22] Corey, E. J. Angew. Chem., Int. Ed. 2002, 41, 1650.

[23] (a) Diels, O.; Alder, K. Ann. Chem. 1926, 450, 237.

(b) Diels, O.; Alder, K. Ann. Chem. 1927, 460, 98.

[24] Desimoni, G.; Faita, G.; Guala, M.; Laurenti, A. Eur. J. Org. Chem. 2004, 14, 3057.

[25] Desimoni, G.; Faita, G.; Guala, M.; Laurenti, A.; Mella, M. Chem. Eur. J. 2005, 11, 3816.

[26] Desimoni, G.; Faita, G.; Guala, M.; Piccinini, F.; Toscanini, M. Eur. J. Org. Chem. 2007, 9, 1529.

[27] Fukuzawa, S. I.; Yahara, Y.; Kamiyama, A.; Hara, M.; Kikuchi, S. Org. Lett. 2005, 7, 5809.

[28] Li, C.; Wang, H. CN 101116828, 2006 [Chem. Abstr. 2008, 148, 308326].

[29] Sudo, Y.; Shirasaki, D.; Harada, S.; Nishida, A. J. Am. Chem. Soc. 2008, 130, 12588.

[30] Harada, S.; Toudou, N.; Hiraoka, S.; Nishida, A. Tetrahedron Lett. 
2009, 50, 5652

[31] Hiraoka, S.; Harada, S.; Nishida, A. J. Org. Chem. 2010, 75, 3871.

[32] Harada, S.; Morikawa, T.; Nishida, A. Org. Lett. 2013, 15, 5314.

[33] Mikami, K.; Kotera, O.; Motoyama, Y.; Sakaguchi, H. Synlett 1995, 975.

[34] (a) Kobayashi, S.; Sugiura, M.; Kitagawa, H.; Lam, W. W. Chem Rev. 2002, 102, 2227

(b) Kobayashi, S. In Topics in Organometallic Chemistry, Vol. 2, Ed.: Beller, M., Springer, Berlin, 1999, p. 77.

(c) Shibasaki, M.; Yamada, K.; Yoshikawa, N. In Lewis Acids in Organic Synthesis, Ed.: Yamamoto, H., Wiley, Weinheim, 2000, Chapter 20.2.

(d) Aplander, K.; Ding, R.; Lindstrom, U. M.; Wennerberg, J.; Schultz, S. Angew. Chem., Int. Ed. 2007, 46, 4543.

[35] Qian, C.-T.; Wang, L.-C. Tetrahedron Lett. 2000, 41, 2203.

[36] Furuno, H.; Kambara, T.; Tanaka, Y.; Hanamoto, T.; Kagawa, T.; Inanaga, J. Tetrahedron Lett. 2003, 44, 6129.

[37] Furuno, H.; Hanamoto, T.; Sugimoto, Y.; Inanaga, J. Org. Lett. 2000, 2, 49.

[38] Tiseni, P. S.; Peters, R. Org. Lett. 2008, 10, 2019.

[39] Zhu, Y.; Xie, M.-S.; Dong, S.; Zhao, X.-H.; Lin, L.-L.; Liu, X.-H.; Feng, X.-M. Chem. Eur. J. 2011, 17, 8202.

[40] Xu, Z.-H.; Liu, L.; Wheeler, K.; Wang, H. Angew. Chem., Int. Ed. 2011, 50, 3484.

[41] Luan, Y.; Barbato, K. S.; Moquist, P. N.; Kodama, T.; Schaus, S. E. J. Am. Chem. Soc. 2015, 137, 3233.

[42] (a) Ishitani, H.; Kobayashi, S. Tetrahedron Lett. 1996, 37, 7357.

(b) Kobayashi, S.; Nagayama, S. J. Am. Chem. Soc. 1996, 118, 8977.

[43] Chen, Z.-L.; Lin, L.-L.; Chen, D.-H.; Li, J.-T.; Liu, X.-H.; Feng, X,-M. Tetrahedron Lett. 2010, 51, 3088.

[44] Jørgensen, K. A. Angew. Chem., Int. Ed. 2000, 39, 3558.

[45] Deng, Y. M.; Karunaratne, C. V.; Csatary, E.; Tierney, D. L.; Wheeler, K.; Wang, H. J. Org. Chem. 2015, 80, 7984.

[46] Hrdina, R.; Guenee, L.; Moraleda, D.; Lacour, J. Organometallics 2013, 32, 473.

[47] Xiao, Q.; Young, K.; Zakarian, A. Org. Lett. 2013, 15, 3314.

[48] Young, K.; Xiao, Q.; Zakarian, A. Eur. J. Org. Chem. 2013, 11, 2337.

[49] Gothelf, K. V.; Jorgensen, K. A. Chem. Rev. 1998, 98, 863.
[50] Frederickson, M. Tetrahedron 1997, 53, 403.

[51] Hashimoto, T.; Maruoka, K. J. Am. Chem. Soc. 2015, 115, 9653.

[52] Yamamoto, H.; Hayashi, S.; Kubo, M.; Harada, M.; Hasegawa, M.; Noguchi, M.; Sumimoto, M.; Hori, K. Eur. J. Org. Chem. 2007, 17, 2859.

[53] Gucma, M.; Gobiewski, W. M. J. Heterocycl. Chem. 2008, 45, 241.

[54] Gobiewski, W. M.; Gucma, M. J. Heterocycl. Chem. 2008, 45, 1687.

[55] Gucma, M.; Gobiewski, W. M. Catal. Sci. Technol. 2011, 1, 1354.

[56] Suga, H.; Inoue, K.; Inoue, S.; Kakehi, A.; Shiro, M. J. Org. Chem. 2005, 70, 47.

[57] Padwa, A.; Weingarten, M. D. Chem. Rev. 1996, 96, 223.

[58] Padwa, A.; Hornbuckle, S. F. Chem. Rev. 1991, 91, 263.

[59] Suga, H.; Shimoto, D.; Higuchi, S.; Ohtsuka, M.; Arikawa, T.; Tsuchida, T.; Kakehi, A.; Baba, T. Org. Lett. 2007, 9, 4359.

[60] Suga, H.; Higuchi, S.; Ohtsuka, M.; Ishimoto, D.; Arikawa, T.; Hashimoto, Y.; Misawa, S.; Tsuchida, T.; Kakehi, A.; Baba, T. Tetrahedron 2010, 66, 3037

[61] Suga, H.; Hashimoto, Y.; Yasumura, S.; Takezawa, R.; Itoh, K.; Kakehi, A. J. Org. Chem. 2013, 78, 10840.

[62] Chen, W.-L.; Lin, L.-L.; Cai, Y.-F.; Xia, Y.; Cao, W.-D.; Liu, X.-H.; Feng, X.-M. Chem. Commun. 2014, 50, 2161.

[63] Kobayashi, S.; Kawamura, M. J. Am. Chem. Soc. 1998, 120, 5840.

[64] Evans, D. A.; Song, H.-J.; Fandrick, K. R. Org. Lett. 2006, 8, 3351.

[65] Barros, M. T.; Faísca Phillips, A. M. Tetrahedron: Asymmetry 2010, $21,2746$.

[66] Tonoi, T.; Mikami, K. Tetrahedron Lett. 2005, 46, 6355.

[67] Narasaka, K.; Hayashi, Y.; Shimadzu, H.; Niihata, S. J. Am. Chem. Soc. 1992, 114, 8869.

[68] Fan, B.-M.; Li, X.-J.; Peng, F.-Z.; Zhang, H.-B.; Chan, A. C. S.; Shao, Z. H. Org. Lett. 2010, 12, 304.

[69] Aggarwal, V. K.; Belfield, A. J. Org. Lett. 2003, 5, 5075.

[70] France, S.; Wack, H.; Hafez, A. M.; Taggi, A. E.; Witsil, D. R.; Lectka, T. Org. Lett. 2002, 4, 1603.

[71] Calter, M. A.; Tretyak, O. A.; Flaschenriem, C. Org. Lett. 2005, 7, 1809.

[72] Huang, Y.-Z.; Calter, M. A. Tetrahedron Lett. 2007, 48, 1657.

[73] Kakei, H.; Sone, T.; Sohtome, Y.; Matsunaga, S.; Shibasaki, M. J. Am. Chem. Soc. 2007, 129, 13410. 